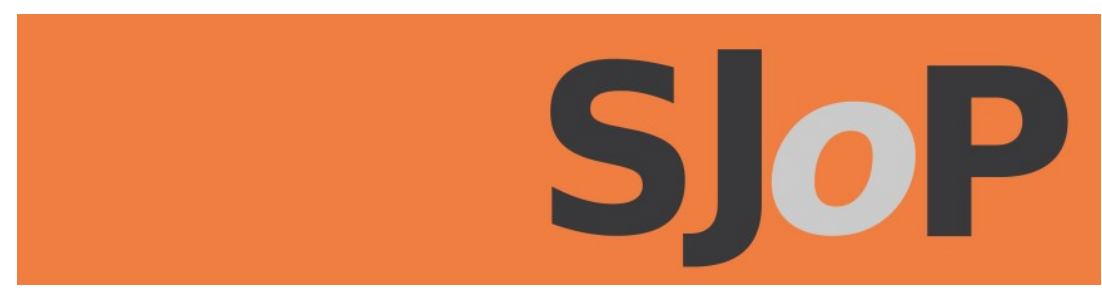

Scottish Journal of Performance

Volume 6, Issue 1

July 2019

ISSN: 2054-1953 (Print) / ISSN: 2054-1961 (Online)

www.scottishjournalofperformance.org

SJoP is supported by

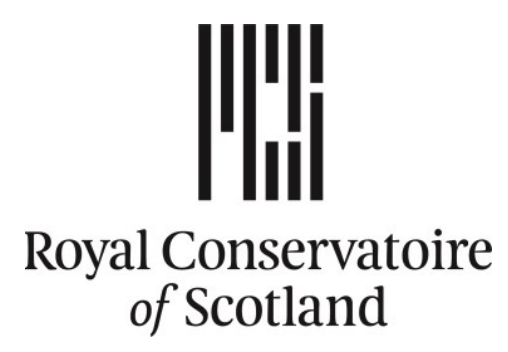




\section{About us}

The Scottish Journal of Performance is an open access refereed journal which aims to promote and stimulate discussion, development and dissemination of original research, focusing both on performance in Scotland (contemporary and historical) and / or wider aspects of performance presented by scholars and reflective practitioners based at Scottish academic institutions.

Published bi-annually and run by doctoral students, the Scottish Journal of Performance welcomes submissions from both established and early career researchers and operates a peer review system ensuring presentation of quality research in performance.

Performance in this context encompasses a wide range of arts and entertainment and takes as central themes dance, drama, film, music and television. The Scottish Journal of Pertormance takes as a key focus the creation and execution of performance in various contexts, encouraging the adoption of a wide range of range of research methods and approaches.

Editorial Team

Co-editor: Iain Harvie (Royal Conservatoire of Scotland)

(editors@scottishjournalofperformance.org)

Co-editor: Anika Marschall (University of Glasgow)

(editors@scottishjournalofperformance.org)

Web Editor: Lucy Hollingworth (Royal Conservatoire of Scotland)

Copy Editor: Bethany Whiteside (Royal Conservatoire of Scotland)

Editorial Advisory Board

Professor Stephen Broad (Royal Conservatoire of Scotland)

Dr Ben Fletcher-Watson (University of Edinburgh)

Dr Sophia Lycouris (University of Edinburgh)

Wendy Timmons (University of Edinburgh)

Dr Bethany Whiteside (Royal Conservatoire of Scotland)

\section{Copyright information}

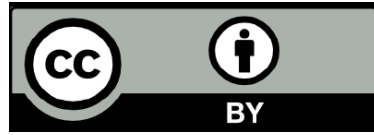

This work is licensed under a Creative Commons Attribution 4.0 International License.

See http://creativecommons.org/licenses/by/4.0/ for details. 


\section{Contents}

5

Editorial

ANIKA MARSCHALL \& IAIN HARVIE

11

Weaving patterns in performance: dramaturgy and the art of performance interpreting CATHERINE KING

31

The practice of solidarity through the arts: inter-relations and shared moments of creation in Share My Table CATRIN EVANS

55

Practitioner Report: 'Where are you from? A woman's body': Navigating notions of belonging through poetry and playwriting with refugees and asylum seekers HELENE GRØN

Performance Review: -ish, by Aby Watson LUCY HOLLINGWORTH

85

Performance Review: -ish, by Aby Watson TIMOTHY COOPER

91

Performance review: Tide Times, by Timothy Cooper \& Laura Bissell GREGOR FORBES

97

Performance Review: Creating Intimacy, by Shona Mackay JAMES SLIMINGS

Book Review: Twenty theatres to see before you die: a love letter to Britain's theatres, by Amber Massie-Blomfield BEN FLETCHER-WATSON 



\section{Editorial}

ANIKA MARSCHALL \& IAIN HARVIE

DOI: 10.14439/sjop.2019.0601.01

Publication date: 14 July 2019

\section{Hope, radical inclusivity and artistic collaboration in times of political uncertainty}

In heightened times of political uncertainty about the future, this issue of the Scottish Journal of Performance invites the reader to hope. Hope is a slippery, messy, yet powerful affective narrative, which does not always directly point to the future, but yet compels us to move forward, to make creative forms of change, to act in solidarity and to transform our social imaginations. But hope is also inherently linked to hopelessness, as Mary Zournazi suggests in Hope: new philosophies for change (2002, p.15), hope as that 'what sustains life in the face of despair'. During the editing of this issue, we were often to face the feeling that our political times might be catalyst to the loss of hope: a continued, unresolvable negotiation on Brexit at Westminster, consequent emotionally heated divisions across the country and continuous right-wing populist xenophobia against immigrant and refugee communities. The contributions curated here powerfully counter this feeling; their narratives, theatre practices, artistic methods and performances are indeed hopeful, generating a more joyful and crucially, liveable present.

Our contributors give hope, by reflecting and analysing on how to not only make political art, but how to make art politically-to paraphrase the renowned film poet JeanLuc Godard. It is a pleasure to host our first editorial for the Scottish Journal of Performance, because this issue continues the journal's young tradition to celebrate a diversity of voices and create space for a range of progressive methodological approaches to art making. In this issue, the authors reassess the political stakes of 
performance and consider the potency of new encounters and collaborative forms for meaning-making. Our contributors' lived experiences and emancipatory art practices confront wider historical legacies and violence against marginalised communities, and they challenge dominant knowledge-power relations based on ableist, racist and citizen-ist practices of exclusion.

The feminist scholars Rebecca Coleman and Debra Ferreday write in the Journal for Cultural Research 14(4) (2010) that hope is 'central to marginal politics which speaks of desires for equality or simply for a better life'. This issue maps a wider cultural desire to express a new critical and creative togetherness in times of conflict, mapping new responsibilities in both artistic and scholarly workings for a progressive politics of equality. These responsibilities are not mapped through a linear, neat, concise creative product, but emerge when focussing on the often invisible, exhaustive, transformative ethics and messy forms of collaboration, rehearsal and devising process. The process of granting each other creative agency, of continuous learning and the social reality of labouring bodies takes centre stage in this issue. Making critical reflections public in a peerreviewed academic forum like this journal, also means a radical act of sharing and carries the weight of activist engagement in the academy. At times, the discomfort with and negotiation of the ethics of research goes unpublished, but here, we aim to contribute to a futurity of practice-based-research which allows for the scholar's particular vulnerability as well as turning traumatic, marginalised lived experiences into creative forces.

Catherine King continues the journal's engagement with the progressive research and art practices coming out of the Royal Conservatoire Scotland and its educational programmes on Sign Language Interpreted Performances for diverse audiences. In Weaving patterns in performance: dramaturgy and the art of performance interpreting, King discusses the theatre industry's aim to make theatre accessible for Deaf audiences, and critically sheds light on her experience as performance interpreter. 
She considers five guiding principles to take seriously and understand the interpreting work during performance rehearsals and on stage as dramaturgically-driven undertaking, which contributes to a richer, more diverse creative landscape for all, audiences, actors and directors.

'Equal access to unjust systems is not liberation. Just because they give you a seat at the table, doesn't mean they want you to eat at the table'-poignantly, Suhaiymah Manzoor-Khan made clear in her spoken-word performance at the University of Kent on 20th March 2019 that access or representation does not always already mean inclusive practice. In her deep self-reflexive analysis of devising workshops with marginalised immigrant communities, the artist researcher Catrin Evans wrestles with Western-centric, logo-centric epistemology and asks how an artistic workshop space might foster radical inclusivity. By engaging with the wider project of decolonisation, her analytic focus is on the collaborative participatory multi-art form project Share My Table which explored media representation of asylum seekers and refugees in Glasgow and beyond. Drawing on bell hooks and James Thompson, Evans argues that only through careful, embodied and affective attention on the ethics of collaboration, on the doing, art practice becomes a meaningful counter to dominant media narratives.

Helene Grøn's practitioner report opens wider discussions about belonging. Grøn carefully describes a series of playwriting workshops she undertook with refugee communities in both Glasgow, and in a detention centre near Copenhagen. She interweaves theoretical concepts of hospitality, a reflection on her embodied, ethical encounters with the communities. Through the communities' poetic responses to the contested question 'where are you from?', Grøn argues for the capacity of playwriting to make a diversity of voices affectively heard and thus, unsettle cultural norms of belonging. 
Replacing the question of 'where are you from' with 'how far can you go' underlies the two performance reviews of Aby Watson's dance performance -ish. Lucy Hollingworth engages a careful and joyous review vocabulary by reflecting on her audience experience of -ish. Hollingworth's review draws attention to the performance's affectual residues and celebrates the creative inspiration and energy that comes with Watson's dyspraxic movement. We editors have juxtaposed her review with one by Timothy Cooper of the same performance -ish, giving critical insight into the generative nuances of contemporary dance. Cooper explores the paradigmatic postmodern question of performing self in performance and here in particular, the question of performing self as dyspraxic dancer. In his review, Cooper analyses how Watson represents her embodiment of a research persona on stage and the 'showing doing' of her fragile creative process behind the performance as vital part of the performance itself. Through their critical generosity Hollingworth and Cooper find liberatory and affective force in the dancer's perceived failures, imperfections and bodily exhaustion.

Tide Times is created by the theatre maker Laura Bissell and the electroacoustic composer Timothy Cooper. It presents a multi-disciplinary and site-responsive installation on Cramond Island on the East Coast of Scotland which ran during the summer months of 2018. In his review, Gregor Forbes elaborates on the island's rich geography, weather and the atmospheric soundscape which Bissell and Cooper explore in their installation through storytelling, walkabouts, poetry, sonic field recordings and displayed found objects.

James Slimings reviews Shona Mackay's Creating Intimacy, a one-to-one performance including video and a pre-recorded string quartet soundtrack. Slimings starts his review not at the beginning of the performance piece itself, but by looking closely into its institutional surroundings and the emotional status and habitus Slimings finds himself in before entering the performance. Creating Intimacy unfolds in a personal 
setting which re-enacts Mackay's private living room. By offering space for intimate conversation with each audience member, as well as a curated peak into her personal composer diary, Mackay creates a profound personal connection with her audiences, that Slimings, as he recounts, is deeply affected by.

In Twenty theatres to see before you die: a love letter to Britain's theatres, Amber Massie-Blomfield portrays a personally selected range of theatre venues across Britain and the histories of the people behind the theatres, by drawing on architecture, historical context, contemporary performance and venue management. In his review, Ben Fletcher-Watson sheds particular light on MassieBlomfields analysis and portrayal of Edinburgh's Summerhall and the way the city becomes the real stage during the festival time each August-currently, being highly contested by local civic movements. FletcherWatson joins in with the author and invites readers to write their own love letters, to draw up and explore their personal map of favourite theatres.

This editorial and issue also present a love letter, dedicated to the critical thinkers, creative performers and theatre makers who make Scotland not only liveable but a hopeful, diverse and inclusive home in times of political uncertainty. Finally, the whole SJoP team would like thank Benjamin Redman for all his hard work, dedication and contributions to fostering cutting-edge research from emerging scholars and art practitioners, having been coeditor for the past three issues. We would also like to thank the Royal Conservatoire of Scotland for their continued support, the editorial team, advisory board, our peer reviewers, funders, and especially our authors.

ANIKA MARSCHALL \& IAIN HARVIE

Co-editors, Scottish Journal of Performance 
Scottish Journal of Performance

Volume 6, Issue 1 


\title{
Weaving patterns in performance: dramaturgy and the art of performance interpreting
}

\author{
CATHERINE KING
}

DOI: $10.14439 /$ sjop.2019.0601.02

Publication date: 14 July 2019

Performance interpreters (PIs) working between English and British Sign Language often work alone to translate performance texts with little or no access to the creative team and are generally untrained in the specific skills required for the performance setting. In addition, the current theatre industry tends to adopt a mechanised approach to access that takes little or no account of the creative aspects of translation and interpreting work. In response to this, and to facilitate a conversation about the performance aspects of the work of the PI, this article discusses the concept of dramaturgy and considers its application to performance interpreting. The article draws on a practice-based project which embedded three PIs in a theatre production of Henry $\mathrm{V}$ at the Royal Conservatoire of Scotland and argues that performance interpreting can be framed as a dramaturgically-driven undertaking, rather than an interpreting task. The article sheds light on this frame's effects on the PIs' processes, and on the experience of the director and cast members. It proposes and evaluates five guiding principles for a dramaturgically-driven frame for use by directors of performance interpreting.

Keywords: BSL, interpreting, dramaturgy, performance, Shakespeare

\section{Introduction}

Research has shown that interpreting is complex and nuanced, requiring a skill of synthesis and contextualising 
not generally necessary in everyday conversation (Roy, 2000; Janzen, 2008; Napier, 2002). The interpreter's task is to listen with an intensity beyond that of the everyday, to question and examine every concept presented to her, to connect people and ideas, and to facilitate the bridging of the gap between cultures and languages. Interpreters who work with the language combination British Sign Language (BSL) and English are generically trained in the UK. They work across a range of fields, such as education, social services, medicine and law, and may gravitate towards a specialism as their career develops. There is generally little or no specific post-qualification training available for these specialisations, including the focus of this article. For some, years of performance work and a chance encounter with BSL lead them to becoming learners of the language and then on to interpreter training; others find that working at nativity shows or local school plays from the earliest years of their community interpreting career sparks an interest in performance which they pursue. For those rooted in the Deaf Community as Children or Siblings of Deaf Adults (CODAs / SODAs), bilingualism is a means of creative expression in the arts. However they find themselves in the field, the performance interpreter (PI) undertakes a unique set of tasks which includes literary analysis, translation, performance and audience engagement. These are all in addition to, and sometimes in conflict with, the task of interpreting.

For theatre audiences, the image described by Siobhan Rocks (2011, p.84) of the lone interpreter standing on the side of the stage 'usually dressed in black... lit in a fixed spotlight throughout the performance, including blackouts and scene changes' is the enduring image of 'accessible' theatre. There is a temptation to see this lone PI as the one responsible for telling Deaf people in the audience what is happening in the play, with the theatre and creative team absolved of accountability for what is happening in the space. This is often perceived as the cheapest option for theatre companies wishing to meet their legal obligation for 'access' as outlined in UK legislation (Richardson, 2017). It is, however, the system that the BSL using Deaf audiences dislike and complain 
about the most, a system where the physical separation of the interpreter can be seen as representing the cultural othering of BSL. It also risks compounding the negative societal stereotype that Sign Language is a language of utility, not of creativity (Schmitt, 2017). Whilst the traditional role of the interpreter emphasises strict criteria for role and boundaries, the PI can feel hindered in her work by these. Early interpreting models, such as the conduit model, have been found wanting (Pöchhacker et al., 2015; Roy, 2000) and, therefore, a new framework of understanding is required to accurately describe the specialist activity of performance interpreting, one that accommodates more appropriately the scope and motivations of the work. This article is intended as a contribution towards shaping such a framework.

Mainstream theatre industry thinking can be rather mired in the language of mechanisation and commodification with respect to performance interpreting. BSL users are informed when the interpreted performance date will be-usually a single date in a much longer run-and the theatre is content that its responsibility for access has been met. An interpreter is sought and booked after the date is advertised and preparations are made. The main drivers are usually to minimise impact on budgets and 'normal' staging practices. Theatres regularly cite the small number of BSL using audience members relative to restricted production budgets as a reason for their choices, not considering that, as Taylor (quoted in Turner and Behrndt, 2016, p.196) puts it, 'the diversity of theatre flourishes with increased audience contact, which is not synonymous with larger audiences'. Attention to the structure and art of the interpreted performance can be what attracts those larger audiences. In a debate reduced only to finance, the spirit of performance can be lost.

At the opposite end of the spectrum are productions created by Deaf performers who use BSL; performances rooted in the language and culture of Deaf communities and performed by Deaf actors. Interpreters are rarely required to work on stage in such productions and so they fall outwith the scope of this research. A few select and 
notable companies in the UK work with an inclusive practice approach and create productions with BSL and audio description built into the performance. Companies such as Birds of Paradise, Graeae and the Deaf Hearing Ensemble bring an inclusive ethos to their work with diverse casting as a norm. These kinds of productions are built with BSL as an intrinsic language of the piece, usually featuring Deaf performers, and again fall outwith the scope of this research.

The research described in this article focuses on mainstream theatre productions which incorporate BSL interpreting by PIs. These kinds of production are still the majority of performances seen by Deaf audiences and are most often cited as being frustrating in that they can feel disjointed or lacking in creative cohesion. This article contributes to the movement to shift the performance industry to a more holistic and inclusive practice. It draws on my practice-based research with a theatre production to argue that working with the PI in a theatrical setting can be more effectively framed as a dramaturgicallydriven activity than an interpreting task.

\section{Dramaturgy and performance interpreting: a case study}

Working with classical texts in performance is a challenge for all those involved. For interpreters and translators, they present specific challenges whose solutions can often feel inadequate. Archaic vocabulary, obsolete concepts and political contexts foreign to the twenty-first century audience present significant issues for the translator and interpreter. This is compounded by the canonical positioning of Shakespeare and his peers in the Western world and the need to balance the source and target text against audience engagement. Whilst performers work for several weeks in a collaborative process with a creative team, the PI responsible for translating and performing the text often toils alone to create a performance text which is then performed with little or no rehearsal with the cast. But crucially, the transition from page to performance is filled with 
journeys, ideas and ghost trails of avenues not pursued: these inform the final production and can also inform and help create the final translation and PI performance. Access to the rehearsal process is, therefore, of great importance.

The production this research discusses, an adaption of Shakespeare's Henry $V$, presented a meaningful opportunity to interrogate the many issues raised when approaching a classical text in a performance setting whilst working collaboratively with a director, actors and three PIs. The research took as its central tenet, 'Don't let's ask what [classical text]... is for, but let's ask what goes on in it' (Barton, 2009, p.25). Throughout the following discussion, my research seeks to frame translation concerns as dramaturgical, rather than purely linguistic or cultural.

The production process was specifically designed to interrogate the notion that performance interpreting, rather than presenting challenges for a production, offers opportunities and possibilities for augmentation if viewed through a dramaturgical lens. Dramaturgy has varied and disparate meanings and this article draws on Proehl et al, who have defined it as 'that set of elements necessary to the working of a play at any moment in its passage from imagination to embodiment' (Proehl et al., 2012, p.20). I will question whether interpreting challenges in a performance are more meaningful when framed as dramaturgically-rooted.

The True Chronicle History of Henry V, with his battle, fought at Agincourt in France, as it hath been Sundry Times played by The Right Honourable Lord Chamberlain His Men by William Shakespeare (hereafter referred to as Henry $V)^{1}$ was produced by the Royal Conservatoire of Scotland (RCS) and Bard in the Botanics, and performed by postgraduate students in the Masters course Contemporary and Classical Text (MACCT) at the RCS. The production was conceived to afford equal space for the BSL interpretation throughout the rehearsal process 
and in all five subsequent live performances. From rehearsal to performance, I took on the dual role of one of three PIs performing in the production as well as Director of Performance Interpreting (DoPI), a role only rarely included in creative teams. The production was directed by Dr Marc Silberschatz. It was funded by the RCS, with an Athenaeum Award, and took place at the RCS in early March 2018.

The performance was staged in a thrust ${ }^{2}$ configuration, located in a pub with a minimal set; a small bar area positioned upstage left and a pool table in the midupstage area. The audience were seated loosely on three sides of the performance area at cabaret style tables which facilitated the director's ambition to create a social space which could include the spectators as variously members of the court, rank and file soldiers or drinkers in the tavern. Battle scenes were replaced with songs chosen by the ensemble and director.

\section{Dramaturgical Principles guiding the DoPI}

To prepare for the production, I created a set of underlying principles to guide me throughout the production process. These were a mixture of aspirational principles and statements of intent which served as reminders of the research focus. These principles were pasted prominently into my script-book and became guiding tenets throughout the rehearsals and performances. They became my support structure for each scene and guidance for decisions taken on staging and intent. Although there were initially ten such principles, this article discusses how the production process drew on five.

\section{Meaning is paramount}

The sense that classical text language is frozen text and has a great deal of cultural weight can bring the interpreting process to a standstill so that translation 
choices are adversely affected. In this production, the language was to be translated specifically with mindfulness of the great range and scope of BSL, rather than the shape or influence of the source language. In accordance with the director's vision, the interpretation was designed to be as open to the audience as possible with no convoluted or difficult to read language constructions, and with meaning as our prime motivation in every line and couplet. To that end, we supported our translations by working with each actor's understanding of what their character was communicating; we relied on the director's considerable understanding of the text, turned to each other for support and gathered all available video sources of Shakespeare as rendered by Deaf BSL using actors. The ambition was to avoid falling into the trap of 'museum Shakespeare' (Hartley, 2005, p.17) and to offer something that was vital, dynamic and rooted in the language of the BSL using community. There is a school of thought that Shakespeare is too difficult to be presented as interpreted work (Richardson, 2017). The project did not want to contribute to this belief but attempted to offer the whole audience an engaging and visually appealing experience.

One of the project's aims was that the BSL using audience should be able to access the story and themes of the play easily, thus allowing for an emotional engagement with the characters and their relationships. We were mindful of the intent of Shakespearean textual features such as blank verse and rhyming couplets and found it useful to analyse the latter, in terms of translation, as a dramaturgical rather than linguistic process. The intent of the couplet rather than the lexical content offers the translator more scope to work into a target language effectively. I worked through the script extracting every rhyming couplet and it became clear that in this production these were most often to be found at the end of scenes, spoken by characters as they were either leaving the stage or exhorting the audience to use their imagination to move the action to the next scene, for example; 'Now forth, Lord Constable and Princes all / And quickly bring us word of England's fall' (Act 3, Sc.4). 
There is a sense of movement in these packages of language and often an encouragement that the audience should do, feel or think something and this was echoed in the BSL translation. Translation choices took into consideration the need for rhythm over rhyme, for energy over specific lexicon being presented.

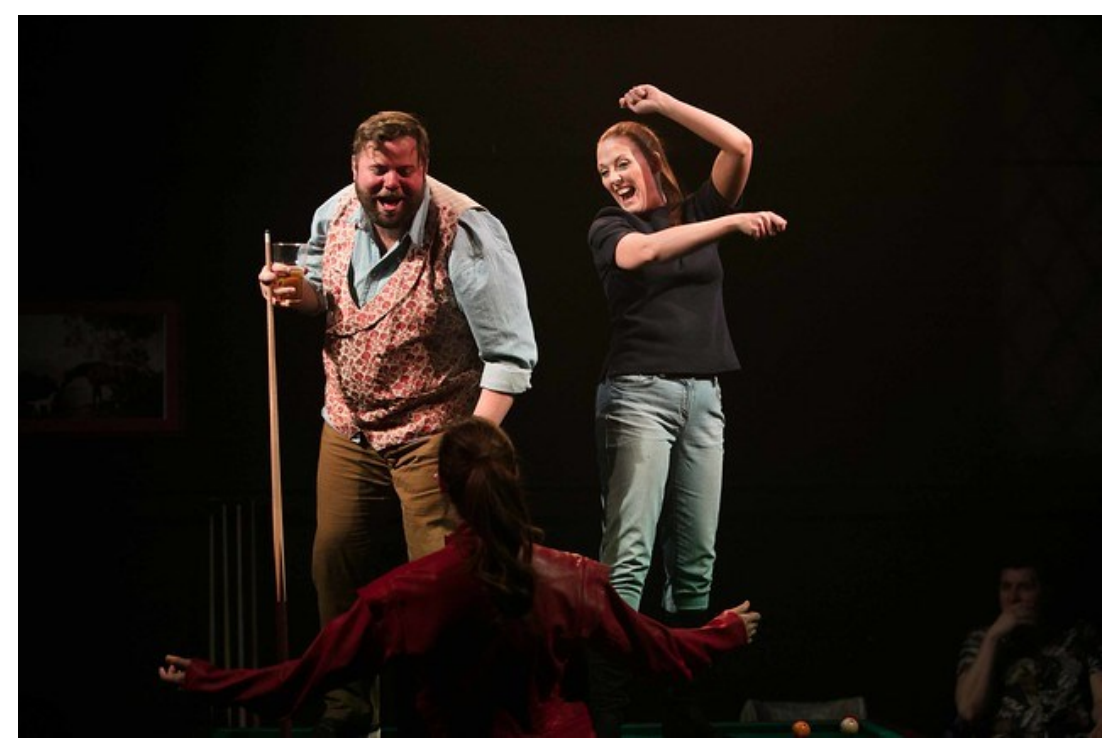

The rhythm of language. Photo: Robert McFadzean.

Similarly, considering that blank verse is 'very often the vehicle for naturalistic speech' and that 'poetry does not necessarily have anything to do with verse' (Barton, 2009, p.46), the wider translation was based on finding dramaturgical meaning rather than rhyme, and offering that to the audience. The performance text created took this as its touchstone and crafted speeches, monologues and dialogue in the natural rhythm of BSL with the explicit intention of fully engaging the BSL using audience on an emotional level; to offer them 'a theatre which dances' (Barba, 2010, p.24).

\section{Nobody should get eye strain watching us}

It has become clear to me working in the field that, the more the PI is separated or even ignored in the space, the more her presence adversely affects the whole audience 
engagement. In many productions stage managers 'block' the interpreter into the space after the play has begun its run and are, necessarily, pragmatic in their approach given health and safety considerations. In the production of Henry $V$, I purposefully avoided this and worked to ensure that the PIs' presence would feel natural, augment the scene, and be dramaturgically meaningful. By this I mean that the relationships between the characters and the PIs would support or reinforce the themes of the play, offer the audience something more about the characters, rather than simply be located in the least problematic health and safety position. In Henry $V$ the cast and PIs worked together throughout the rehearsal period to feel comfortable with each other as performers, working through challenging scenes together to resolve dramaturgical questions and building a sense of ensemble between them.

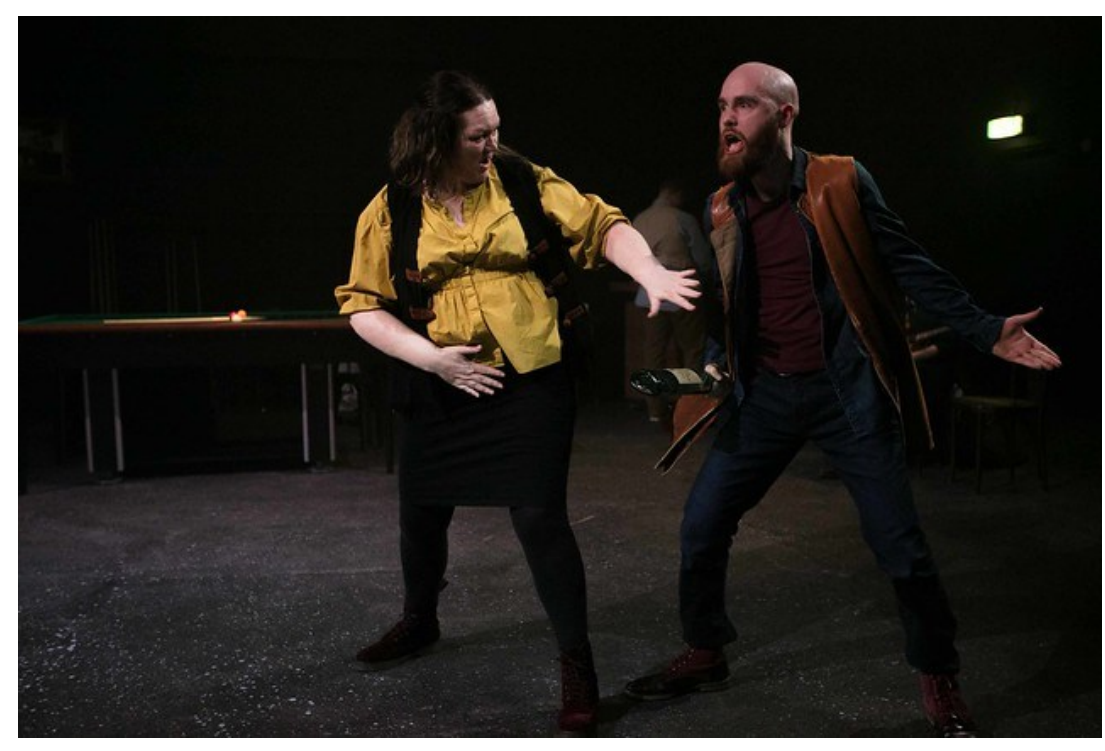

Finding relationships in the ensemble. Photo: Robert McFadzean

The PIs were never reliant on the cast for assisting them in their positioning, but instead, functioned as their fellow drinker in the tavern, their fellow officers in battle and their fellow performers on stage taking their own agency as performers in the space. For example, in Act 2, Scene 4, when Mistress Quickly describes the death of Falstaff, a simple decision was taken to support one PI's instinct to comfort her which wove this kind of blocking into the 
performance. No global choice was made as to which model of interpreting would be utilised throughout the play: each scene was interrogated to understand the rationale, the logic, the emotional impact and the additional information about the play brought by the PI's presence.

\section{Translation challenges are shared problems}

Translation was a major consideration for this project. As previously described, the decision had been taken to avoid any attempt at a more 'Shakespearean' BSL, acknowledging that this would have required much more time and many more skilled collaborators to achieve. Instead, the PIs were asked to translate the text into modern BSL that would convey the pace, intensity of feeling and themes of the production. This did not mean that translation was reductive or devoid of challenge; with a text as complex, as old and as culturally iconic as Henry $V$, there were considerable linguistic and cultural difficulties to overcome. Specific translation challenges such as 'treason' and 'noble line' were discussed a great deal and were finally translated respectively as concepts of violence towards the crown and the concept of familial descendants framed within a physical posture that was positive and indicated high register language use. Working together to discuss the translation challenges enabled the PIs to feel confident in their performance of the translated text and gave them space to find depth in the relationships they created with other characters in performance. Minor performance moments between PIs and actors added depth to the production and offered the audience insight into the characters and their journeysmoments that were not language-based, such as the scene (described above) where the tavern PI comforts Mistress Quickly, the English court PI and Henry sharing a moment of relief after Agincourt, and the French court PI's indignation at Mountjoy's click of the fingers to summon her. These could only begin to emerge once the PIs had moved beyond the fear of translating 'incorrectly'. 
4. Our presence on stage will always be meaningful, make sense, and has no need to be justified except dramturgically

This principle was, in retrospect, the crux of the project. Throughout every rehearsal for every scene we asked questions: Why is there an interpreter in this scene? Who is she? What question does she ask? What effect on the audience is she having? In collaboration with the director, the PIs and the actors, each scene was carefully analysed in response to these questions. There is often a sense that integrating PIs into a performance is a problem; this project sought to move that to a more positive paradigm framed within a dramaturgical approach, and to look for ways that the presence of the PIs in the production could augment each scene. Once the need to justify the presence of a PI was removed from our creative process, this production found that it had three additional performers with whom to ask questions, offer the audience thoughts or challenges and to create images. For example, in Act 3, Scene 3 the English forces have defeated the French at Harfleur and King Henry issues a challenge to the Governor of the city: surrender or be responsible for the horrific consequences. The scene became the pivotal moment in Henry's character journey. It was presented with a darkened stage, a lone Henry in the middle of the space and a single spotlight on the actor. This kind of staging is generally considered highly problematic because the presence of the PI is feared to 'pull focus' from the main actor's performance. In this case, however, the director saw an opportunity to give the audience an additional insight into Henry's state of mind. While the actor presented the speech on the floor of the stage, the PI was placed on the pool table behind and lit from high on the lighting rig with a spotlight that allowed the BSL to be clearly read but with an additional, ominous shadowing. 


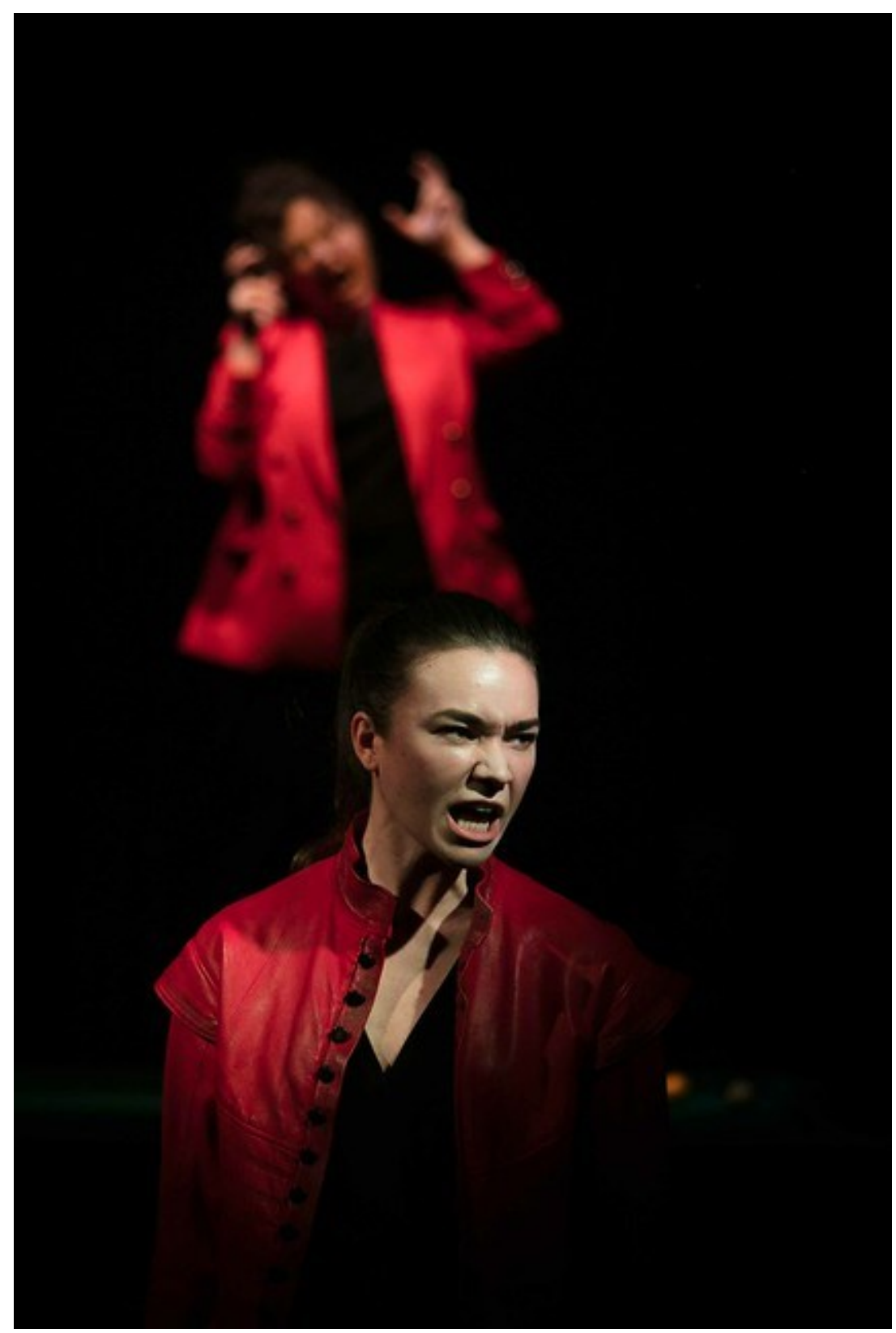

The evocative dramaturgy of Harfleur. Photo: Robert McFadzean.

The direction given to the PI was to find ways to make the translation and performance as monstrous as possible (while true to the target language), a visual representation of Henry's horrific interior landscape. In this way, the PI and BSL were used to augment the scene, to offer the audience an insight into the heart of the character and the brink to which Henry had come. 
If not, why, in a moment look to see

The blind and bloody soldier with foul hand

Defile the locks of your shrill-shrieking daughters,

Your fathers taken by the silver beards,

And their most reverend heads dashed to the walls,

Your naked infants spitted upon pikes,

Whiles the mad mothers with their howls confused

Do break the clouds, as did the wives of Jewry

At Herod's bloody-hunting slaughtermen.

(Act 3, Scene 4).

The translation had to find an arc that echoed the text in shape and emotion, moving from disturbing to horrific in steps and leaps and ending with a breathlessness of anticipation, standing on the precipice of a gulf awaiting the Governor of Harflueur's reply. Placed behind and high above the actor, the PI looked far out into the audience painting images of the possible horror to come. Presenting the external and the internal character simultaneously, we utilised the presence of the PI as an augmentation of the scene and offered the audience what Barba describes as evocative dramaturgy, the 'intimate resonance with the spectator' (Barba, 2010. p.10).

5. The register we use will always be appropriate for the field

All too often, interpreters working on a performance find themselves on stage with no training and little creative support. When working on a theatre stage they can fall back on the one field that feels familiar-conference 
interpreting. It is common to see interpreters in a performance space using a language register that is more appropriate to a conference than a creative endeavour. There is a need to balance this conference register with the very theatricalised language of performance which can feel divorced from the lived language of the Deaf Community. Most interpreters in the UK are generically trained and have experience of working across multiple fields and, with three PIs bringing over fifty years of experience to the production, there was a range of linguistic registers to draw on. We were able to consider the scene, the characters and the story as it was emerging to create a performance text that felt deeprooted in the language of the Deaf Community. We constantly asked ourselves questions, and mined our understanding and knowledge of the Deaf Community to push us beyond superficial translations. This avoided the ethically troubling position of demanding that the BSL using audience stay in the position of feeling removed from the performance, insisting that they should 'appreciate the cultural achievements of the English speaking "host" society' (Turner and Pollitt, 2008). Besides the desire to engage the widest possible theatre audience, there was a tacit underpinning of respect and value of this specific community and its language.

\section{The interpreter experience in the theatre}

Collaboration at this level between a director, cast and PIs is still rare in Scotland with the exception of the aforementioned companies. It is common for a production's ambition to integrate to fall foul of the stress imposed by the demands made on time and resources during the technical week: the PI often being moved further down a long list of priorities.

During the production process of Henry $V$, the integration of PIs as a dramaturgical feature became a logical extension of the overarching dramaturgy of the creative team. For example, questions around Henry's intent in a scene were considered both for the actor and the PI while songs were choreographed so that there was a high level 
of visual engagement which offered the mood and feeling of the music. The presence of the interpreter was examined in each scene in terms of narrative, organic and evocative dramaturgy. As Snyder states, 'an interpretation is a synthesis of a translation, the performances, the lights, the staging, the sound and the audience' (2009. p.127). Taking this further and incorporating the presence and work of the PI into the overall dramaturgy gives a director the opportunity to deepen the interrogation of the text in performance.

Being in rehearsal from the first day allowed the PIs to see performances change day by day as the ensemble discovered the text and characters. This continued in all five performances with new insight and fresh discoveries happening throughout. The translated performance text followed a similar process with decisions made and changed based on the energy of each performance. With each new insight into character, text or relationship, the English performance text transformed and so, necessarily, did the BSL performance text. This level of access for PIs to the rehearsal room brought depth to the translation and performance text. Just as the spoken performance text was a living, breathing thing, so too was the BSL performance text. The idea that the PIs are on stage simply to provide access for the Deaf audience was contested throughout the production: many of the decisions-for example, on thrust configuration sight line challenges and on creating authentic relationships between performers on stage,-were made in relation to how the whole audience would engage with the performance and this, necessarily, applied to the PIs too.

As I have said, there is currently no formal specialist training in the UK for PIs: they generally create an adhoc, hybrid skill base which they then develop working in the industry. An interpreter trained generically who chooses to work as a PI has not only performance skills to acquire but also the technical theatre skills required to function appropriately in a production. Without formal training, this creates an unpredictable skill set across the industry. With funding from Creative Scotland there has 
been an attempt to address this, with a collaboration between National Theatre of Scotland, Solar Bear, Birds of Paradise and SignArts. The project, Creative Licht, is a two-year programme of eight sessions which offers knowledge exchange opportunities for the performance industry and interpreting professionals with masterclasses for interpreters focusing on specific performance areas such as Voice, Body Awareness in performance and Textual Analysis (National Theatre of Scotland, 2019). At time of writing, this highly successful programme is coming to the end of its second year and discussions around its legacy are under way.

There is an ongoing debate on whether PIs should be employed when there are highly skilled and experienced BSL using actors and performers in the country as well as new graduates of the ground-breaking BA Performance in BSL and English at the RCS in Glasgow. Whilst this debate is a valid and necessary one, it would be reductive to frame it as a binary choice and it behoves us to consider a nuance that is too often ignored. It would be an assumption that all BSL using actors wish to be an onstage PI. It could be a rather convenient solution, however, for an industry which struggles to be more diverse in how it casts productions, but I argue that we should resist the urge to automatically categorise every BSL using performer as an interpreter. It risks stripping them of their autonomy as actors, of their agency and their right to take on more interesting character roles that challenge themselves, their audiences and an industry only beginning to inch its way towards genuinely diverse casting. Working with professional PIs as an additional performance discipline moves us into a more positive space in which a creative and collaborative conversation can take place.

\section{Conclusion}

In conclusion, my belief is that framing performance interpreting as a strand of a production's dramaturgy is a fruitful and effective approach which benefits the whole audience. It is a reality in twenty-first century Scotland 
that theatres are expected to offer performances that BSL users can access. As audiences have become more informed and more engaged with performance, they expect greater quality and a more fulfilling experience: it is the responsibility of both the interpreting and performance industry to respond to those expectations.

Where a director considers the presence of a PI in the performance space as something to deal with on a purely functional level, the dramaturgy of the piece may be compromised. The practice-based research outcome from Henry $V$ shows that, if we understand the PI as a dramaturgical agent, productions benefit from increased creative opportunities. I therefore recommend that PIs are present in the rehearsal room as members of the cast and work as part of the ensemble to create the performance text. As I have shown, by absorbing the text and the actor's journey with the text, the PI can move beyond the fear of translating incorrectly and discover those performance moments that are not language-based but offer the whole audience insight into the characters and their journeys.

Alternative staging configurations, such as thrust, do not necessarily exclude the integration of PIs as has been traditionally thought. Given that sight lines become an important consideration for everyone in that kind of performance space, a heightened awareness of the audience is the norm for the whole ensemble, including the PIs. It may be that employing more than the traditional one or two PIs provides solutions and creative opportunities in such situations. The presence of PIs can be incorporated organically into the earliest design stages in order to ensure as much creative space to work with as may be required later in the rehearsal process. What I have also shown in this article is that the role of DoPI is a pivotal support. I argue that including a DoPI as a specialist role in a production, similar to a Movement Director or Lighting Designer, is an important dramaturgical approach to adopt in all productions that strive for a diverse audience. Bringing a specialist skill 
that is both functional and creative, the DoPI offers vital contributions to finding dramaturgical opportunities.

This practice-based research on Henry $V$ demonstrates that both the perfomers' and PIs' dramaturgical sensibility is paramount. To leave the dramaturgy of the PI unwoven risks compromising the delicate and hardwon architecture that makes a successful and enjoyable production for all audiences.

\section{Notes}

1. The production was an edited version of Shakespeare's Henry V (most Shakespeare productions are edited versions of the plays in my experience) and it included text from Henry IV Part One and Henry IV Part Two to provide context to the past relationships of the characters (particularly King Henry's relationship to Bardolph, Pistol, Nym, Hostess Quickly and Falstaff). Staged as a ceilidh play, it also featured eight traditional / folk songs originating from the various cultural contexts of the performers involved. (Note by Dr. Marc Silberschatz). ${ }^{[\uparrow]}$

2. Thrust configuration consists of a stage which protrudes into the auditorium so the audience is on three sides. $\underline{\underline{[\uparrow]}}$

\section{References}

Barba, E., 2010. On directing and dramaturgy: burning the house. London: Routledge.

Barton, J., 2009. Playing Shakespeare. London: Methuen Drama.

Hartley, A. J., 2005. The Shakespearean dramaturg: a theoretical and practical guide. New York, NY: Palgrave Macmillan.

Janzen, T., 2008. Topics in signed language interpreting theory and practice. Amsterdam: J. Benjamins.

Napier, J., 2002. Sign language interpreting: linguistic coping strategies. Coleford: Douglas McLean.

National Theatre of Scotland, 2019. Creative Licht [online] Available at: <https://www.nationaltheatrescotland.com/artistdevelopment/creative-licht/ $>$ [Accessed 22 April 2009].

Proehl, G. S., Kugler, D., Lamos, M. and Lupu, M., 2012. Toward a dramaturgical sensibility: landscape and journey. Madison, NJ:

Fairleigh Dickinson University Press.

Pöchhacker, R, 2016. Introducing interpreting studies. London, New York. Routledge. 
Richardson, M., 2017a. Sign language interpreting in theatre: using the human body to create pictures of the human soul.

TranscUlturAl: A Journal of Trans and Cultural Studies 9(2), pp.4562. [online] Available at: $<$ https://journals.library.ualberta.ca/tc/index.php/TC/article/view/29 265> [Accessed 31 May 2019].

Richardson, M., 2017b. An Instance of Cultural (MIs-)

Communication. Online presented at the Edsign Lecture series, Patterson's Land, Moray House, School of Education, Edinburgh University, March 14. [online] Available at:

$<$ https://www.youtube.com/watch?v=xz_YrjFYruY $>$ [Accessed 14 March 2017].

Rocks, S., 2011. The theatre sign language interpreter and the competing visual narrative: the translation and interpretation of theatrical texts into British Sign Language. In: Baines, R. W., Marinetti, C. and Perteghella, M. eds., 2011. Staging and performing translation: text and theatre practice. Hampshire: Palgrave Macmillan. pp.72-86.

Roy, C. B. ed., 2000. Innovative practices for teaching sign language interpreters. Washington, D.C: Gallaudet University Press.

Schmitt, P., 2017. Representations of sign language, deaf people, and interpreters in the arts and the media. Sign Language Studies 18(1), pp.130-47.

Snyder, L., 2009. Sawing the air thus: American Sign Language translations of Shakespeare and the echoes of rhetorical gesture. PhD, University of Maryland.

Turner, G. and Behrndt, S., 2016. Dramaturgy and performance: theatre and performance practices. London: Palgrave Macmillan.

Turner, G., and Pollitt, K., 2008. Community interpreting meets literary translation. The Translator 8(1), pp.25-47.

\section{About the author}

Catherine King has been interpreting for 25 years and is a first year $\mathrm{PhD}$ student at the Royal Conservatoire of Scotland. Catherine's first performance interpreting job was a pantomime 21 years ago whilst still a trainee interpreter. This was the first pantomime she had ever seen. Since then she has worked extensively in the Scottish performing arts industry and is one of the partners on the Creative Scotland funded project, Creative Licht. Catherine works closely with the National Theatre of Scotland, The Tron Theatre and Theatre Gu Leor and many others and is known for her work interpreting stand-up comedy. 
Scottish Journal of Performance Volume 6, Issue 1 


\section{The practice of solidarity through the arts: inter-relations and shared moments of creation in Share My Table}

CATRIN EVANS

DOI: 10.14439/sjop.2019.0601.03

Publication date: 14 July 2019

In 2017 the Scottish Refugee Council and Tramway embarked on a collaborative participatory arts project seeking to explore the upsurge in media coverage around issues of migration. Share My Table took a multi-artform approach, with performance and visual art providing the foundation for the exploration. This article, written from the position of artist researcher, shifts the lens away from the artistic or performance outputs of this participatory project, and instead reflects and theorises the working practices which emerged throughout the Share My Table project. By drawing on bell hooks's work on practices of freedom (1994), and James Thompson's call for a refocusing towards affect, beauty and care (2011, 2015), the author argues for participatory practice's radical potential. Ultimately, the how of participatory work, the careful and ethical attention on the doing can activate solidarity in relation to the asylum regime.

I see a family standing in a queue

I see an administrator

I see suffering and fear

I see some people are happy

I see talk of danger 
Scottish Journal of Performance

Volume 6, Issue 1

I see stop

I see someone waiting and the traffic light is green

I see praying

I see someone working

I see a family

I see a student

I see

Stop

Extract from collaborative performance poem created by Share My Table project members

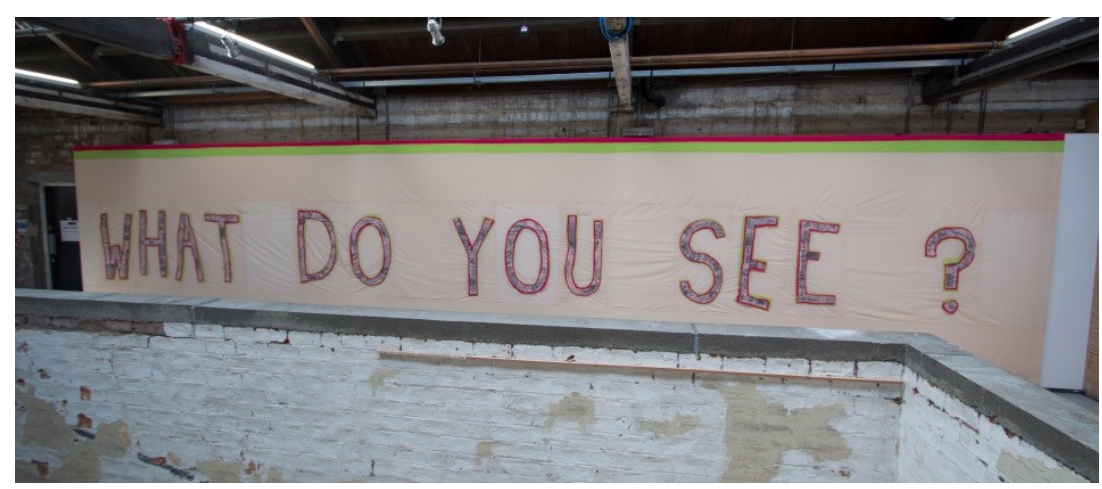

What Do You See?: our large-scale intervention invited audiences to look beyond media headlines and images to consider who is the author, who is the subject, and why? Photo: Najma Abukar.

\section{Introduction and critical context}

In February 2017, the Scottish Refugee Council and Tramway opened the doors to the first gathering of their latest partnership:

We invite you to join Share My Table-a diverse group of people living in Glasgow 
looking to creatively respond to the recent media attention surrounding migration. This multi-artform project brings together people, food and conversation (Scottish Refugee Council, 2017).

The open, public workshop had been advertised widely across the city in multiple languages; amongst integration networks, through community and support organisations, as well as in person by the project coordinator Deborah May at English for Speakers of Other Languages (ESOL) classes, libraries and drop-in centres. The project led by myself (a theatre-maker) and visual artist Elena Mary Harris, was defined as an arts and integration project, and in conversation with the project producers our hope was to gather people from across generations, cultures and countries. In order to encourage a 'two-way process' of integration (Scottish Government, 2013, p.2) the supporting strapline for the invitation read: 'Whether you have been in Glasgow your whole life or for just a week we would love you to be part of this' (Share My Table recruitment flyer, 2017).

Positioned as artist researcher, I balanced two roles throughout the Share My Table project. One as co-lead theatre artist with a brief and a team of partners, whose job it was to develop the project collaboratively with all those involved. The second as an arts-based researcher, whose participation in the project-and ongoing engagement in 'participatory dialogue' or 'a correspondence' (Ingold, 2011, p.241) with everyone involved-would be fundamental to how I was going to examine the relationship between participatory arts practice in Glasgow and the processes of integration undertaken by individuals seeking asylum and those granted refugee status. It would be in the doing of this project, and in the act of 'thinking, talking and writing in and with the world' (p.241) that I would develop the direction of my study. My research and my artmaking processes continually interacted, operating on what can best be described as a feedback loop; reflecting back upon each other through a 'hermeneutic-interpretive 
spiral' (Trimingham, 2002, p.56). I draw attention to my positioning as artist researcher by writing in what James Thompson defines an 'affective register', one that is 'both practice-based and analytical’ (2011, p.7).

My artistic and scholarly work on Share My Table approaches with caution the trend for the arts to be 'reshaped within a political logic' (Bishop, 2012, p.13). New Labour, for example, instrumentalised the arts for the goal of social inclusion or cohesion (p.13), and this has given way to the dominating ideological view that participatory arts' sole societal role is to produce quantifiable effects (Thompson, 2011, p.116). Alongside this, contemporary cultural policies are quick to employ what Simone Weil, and in turn Alison Phipps, would term 'empty words' (Weil, 2005, cited in Phipps, 2014, p.110). Words like empowerment, resilience, agency and social change are 'given capital letters' (p.110) as part of a project or organisational agenda, whilst being simultaneously 'emptied of content and manipulated for absolute ends' (p.111), without rigorous consideration of 'what they can conceal, the justice they may divert and illusion of "good" they may foster' (p.111). Like critical theory, the arts are 'not inherently healing, liberatory, or revolutionary' (hooks, 1994, p.61). They are as much a bedfellow of global capitalism and the violent structures embedded within it, as they are allied in solidarity with those most damaged and marginalised by it (Jelinek, 2013). Particularly in the field of refugee performance, stories risk being extracted, re-contextualised or presented in ways that over-simplify or misrepresent individual experience and complexity (Jeffers, 2012). Work too often tends towards an 'aesthetic of injury' (Salverson, 1999, p.34), a trend in migration discourse more broadly that Ida Danewid argues is leading to an 'erasure of history' and of political responsibility, because

[i]n the context of the European migrant crisis, such a framing has led to an ethics based on mourning and welcoming migrants as universal humans-rather than as victims of a shared, 
global present built on colonialism, racism, and white supremacy (Danewid, 2017, p.1683).

Equally, this research is framed by an engagement with the critical discourse that circulates around the concept of integration. Critics like Melinda McPherson argue that 'integrationism is commonly represented as the middle ground of migration policy'; a compromise between multiculturalism and assimilation seen to appease critics of these two 'extremes' (2010, p. 551). But the reality, Sara Ahmed contends, is that integrating is about homogenising:

[a]lthough integration is not defined as 'leaving your culture behind' (at least not officially), it is unevenly distributed, as a demand that new or would-be citizens embrace a common culture that is already given (Ahmed, 2010, p.47).

Ellie Vasta goes further arguing that the European shift towards integration discourse indicates a 'desire to control difference' (2010, p.505), with ever-hardening conditions that define what an ideal citizen is, to the inevitable exclusion of many. Furthermore, with a large percentage of individuals seeking asylum being integrated into poverty, amidst a high surveillance culture increasingly suspicious of outsiders, and the everpresent risk of indefinite detention, I carry forward the concern held by many scholars working around integration, about what kind of society individuals and families trying to settle in the UK are being expected to integrate into (Mulvey, 2013, p.134).

In this article, I examine the working methods which emerged throughout Share My Table by drawing on bell hooks's work on the practices of freedom. Paying particular attention to the importance of dialogue and collaboration as a foundation of engaged pedagogy, I apply her theory of education on to the how of my own 
artistic practice: in order for artistic practice to fulfil a political or liberatory function, we must 'ask that it do so' (1994, p.61). I will also respond to Thompson's call for participatory practice to 'recognise affect-bodily responses, sensations and aesthetic pleasures' as 'a place from which a particular politics of practice can be developed' (2011, p.7). Thus, I seek to shift the lens away from the artistic and public outputs of Share My Table and towards its process, encounters, interactions and workshop dynamics. I question what it might mean that for many project members, Share My Table made them feel 'as though I am in my family home' (Flower) ${ }^{1}$, or that they were 'not in this world alone' (Joe). I am not attempting to position the project as a blueprint of best practice, or as having constructed some sort of ideal process for other practitioners to model their projects on. Rather, I hope to 'exercise a little critical vigilance' (Phipps, 2014, p.110) in order to shed some light on the practical, ethical and social tensions of Share My Table, and to interrogate what the potential politics of arts and integration might be. I suggest that through an attentiveness to the aesthetic practices in the room, we constructed, even if temporarily, a space of care and solidarity. One that invoked a feeling of being 'really free' (Maham).

\section{The politics of the space in action}

Share My Table's weekly workshops were held in the Studio space of Tramway in the Southside of Glasgow. With large white walls, a high ceiling full of bright windows and a dance-floor at its centre, the room felt quite different from the many community spaces or charity offices that arts projects are often squeezed into. Before the first session Elena and I were concerned that the Studio might be intimidating to walk into, its scale and openness make you visible to all others, wherever you are in the space. There were no obvious shadowy corners for those less sure about their involvement to tuck themselves away. In many ways, this was a gift, but we wondered whether it might put project members off. To counter this, one of the earliest decisions made was to ensure that the space always felt active by creating a 
physical and symbolic structure to the room. The artistic team divided up the space by using chairs and soft benches, into four different areas:

- a working / focused space

- an active observer space

- a break-out / food space

- and outside of the room

We quickly learnt that not only did these sub-spaces allow the room to feel busier to the eye on first arrival, it also helped us establish a set of spatial parameters that allowed project members to access the work at their own pace, with the assurance that they were always part of the working dynamic of the whole Studio. Even though each session started with a shared meal, some individuals would be keen to be active in the working space from the moment they arrived, whilst others would choose to watch from the periphery for almost the entire session. To borrow from Adrian Howells' artistic philosophy, delineating the space enabled us to gently suggest that 'it's all allowed' (Heddon and Johnson, 2016, p.14), an ethos that played out in a multitude of ways as the project developed. Rather than creating rules for the room that felt restrictive, these spatial dynamics created a structured flexibility that invited people to move through the space with ease, testing out the artistic activities and defining the terms of their own engagement. Through this the Studio became a site for enacting one of the central tenets of hooks's theories on practices of freedom, that each individual in the room 'assume responsibility for their choices' (1994, p.19).

My journal notes reveal that this spatial structure did not always feel successful; with up to forty people in workshops, at times I felt some sessions had descended into chaos: 'I worry we are just managing space, rather than holding or facilitating creativity' (Evans, 2017). However, despite-or perhaps in spite of-the anarchic atmosphere that often permeated across our four sub- 
spaces, we committed to this set-up because we began to understand that spatially we were gesturing towards a politics of freedom of movement in the room. Many project members articulated that the space felt quite unique in comparison to other spaces they spent time in, and when invited to engage critically with why this was Alee identified a sense of engaged autonomy:

you can come and you know

you are doing something

you are not coming to listen to someone

or for any information or anything

you are doing something

you are participating in some work

and its very peaceful

nobody

interrupt you

nobody point at you

nobody ask you questions

nobody deal with you like you are school children

like

sit down

here

What I want to draw out of Alee's observation is the importance she places on the absence of feeling like a passive observer being controlled or instructed. With no one saying 'sit / down / here' she suggests that the Studio space was asserting its own performative function; working as a symbolic and material counterpoint to the 
physically restrictive and oppressive spaces of the immigration asylum system, made manifest in the macro and micro-borders, check-points, and regular sign-ins that Alee, and the majority of Share My Table's project members were compelled to spend a disproportionate amount of time in. The Studio space became, in its own unspoken way, part of an ongoing pedagogy of resistance that was emerging within the practices of the project; 'a counter-hegemonic act, a fundamental way to resist' (hooks, 1994, p.2) the everyday oppressive strategies imposed by the British state that dictate the terms of where you are allowed to go, and when you are allowed to participate.

\section{The affect of purpose}

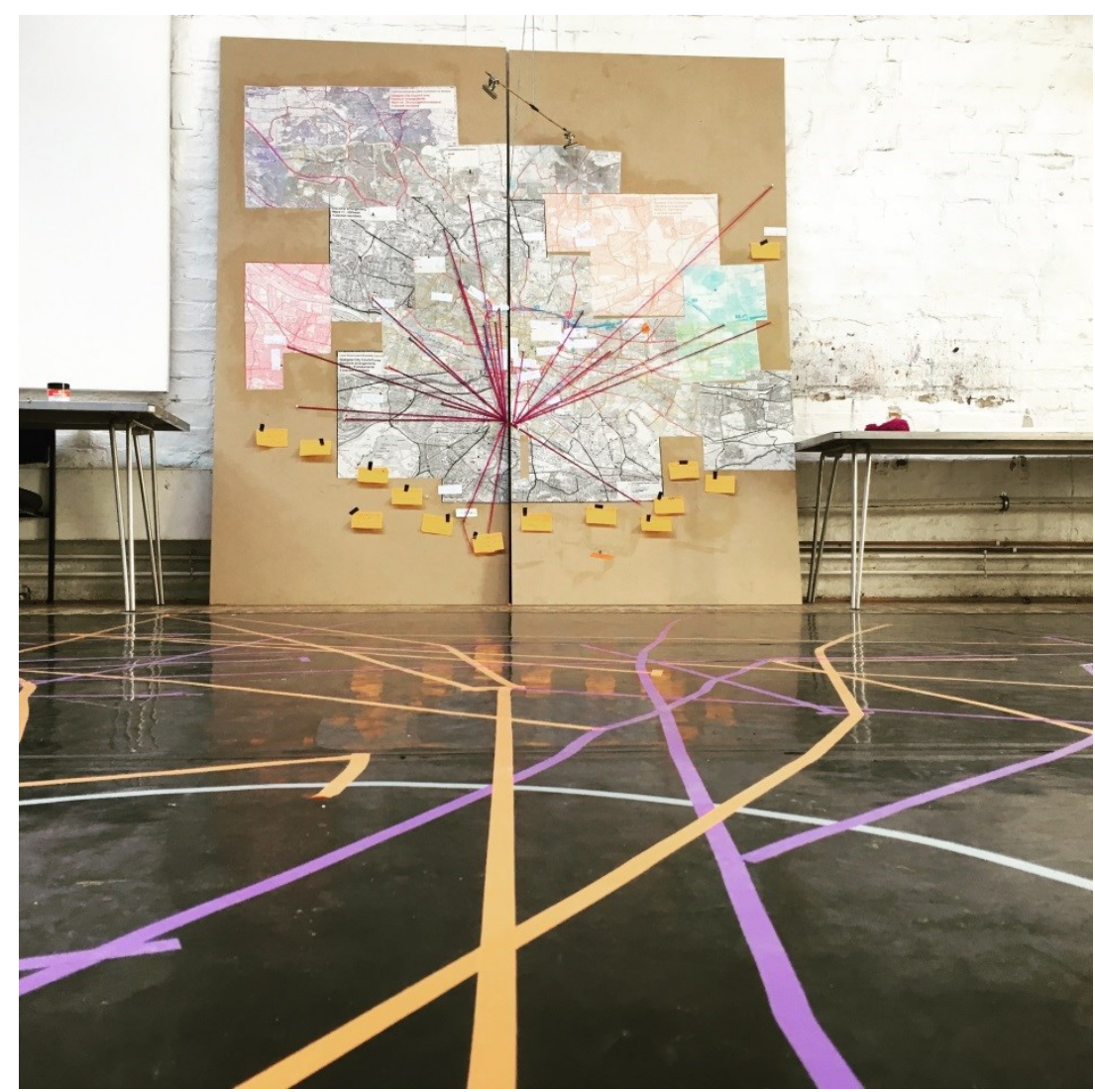

Our Share My Table map: this ongoing exercise saw us chart the journeys we took in order to come together each week, and prompted us to share our experiences of the city. Photo: Elena Mary Harris. 
With each weekly session Elena and I were eager for project members to walk into a space that would feel like an artistic space. Creative debris and evidence of previous arts workshops splattered on the walls helped mark the artistic activity, but we complimented this within each session by ensuring that something was always already happening as people arrived. Whether this was adding to our large collective map, helping organise materials for the session, or gathering round and feeding into the day's discussion topics, we aimed for there to be a palpable sense of doing that individuals could engage with from the outset of each workshop. This speaks directly to hooks's contention that a teacher or facilitator in a space needs to enact an engaged practice-not simply to try and generate it. By embracing 'the performative aspect' of our role, to perform our busyness, we were 'compelled to engage "audiences," to consider issues of reciprocity' (1994, p.11) that challenged us, as the artistic leads, to embody the ways of working we wanted to inspire within the room. In turn, we found that this approach engendered a sense of purpose across the space, a purposefulness that was infectious, permeating into how the workshop itself played out, and thus serving 'as a catalyst that calls everyone to become more and more engaged, to become active participants' (p.11) in the creation of the work, as well as the working practices of the space itself.

In the reflective research sessions I facilitated alongside Share My Table many of the project members drew my attention to a sense of purpose within our activities as a reason they kept returning each week. Lawyer talked about this sense of purpose in relation to a specific workshop where he had entered the space to see and feel a hive of activity that pulled him in. He reflected on the experience as one that had made him feel fully alivesomething he had not felt very often since leaving his home country. The workshop had focused on creating large sculptures made of newspaper throughout the Tramway building, sculptures that deliberately interrupted or disrupted the space. To prepare everyone for this activity, we started the session with a collective task of creating a giant newspaper sculpture that 40 
spanned the diagonal length of the Studio. My own notes reflect the way the group responded:

There was a moment of pause before everyone jumped in-no questions, no resistance, just action with everyone selecting paper and beginning to build. I thought we might just all end up working on our own sections-and for a while this was the case, but very soon groups of activity had emerged-working to best prop up a structure or solving how to connect two seemingly disconnected sections. There was folding, rolling, crunching, scrunching, laughter and the sound of sellotape being pulled and ripped, and as we worked more people arrived and they became absorbed into the activity, no questions asked they just got to work, keen to be part of this shared piece of work... My favourite moment was re-entering the space after having left for a moment, because I hadn't quite realised how many folk had arrived. The room was full, with people making-one person up on a chair hanging something, others gathered around one of the structures working out how best to keep it upright, others deep in construction mode. There was conversation but nothing was distracting from this moment, everyone was making this happen. It was beautiful (Evans, 2017).

The spirit of activity that gripped people as they entered the space operated as an embodiment of collective endeavour, and the beauty that I felt and was moved by in this moment propelled me further to reflect on Thompson's call for an 'attention to affect' in participatory practice (2011, p.117). With reference to Patricia Ticineto Clough (2007) Thompson contends that affect 
is connected both to a capacity for action and to a sense of aliveness, where it is that vitality that prompt's a person's desire to connect and engage (perhaps with others or ideas). It is not a field of particular communicative content, therefore, but rather of capacity and intensity (Thompson, 2011, p.119).

The vitality that I witnessed was emotionally understood as that of being alive for Lawyer. For me, it articulated itself as 'beauty', and whilst the colonial ramifications around definitions of beauty are extensive and require a vigilant critical tangent elsewhere ${ }^{2}$, here I emphasise this encounter in order to demonstrate that 'the work' of participatory arts practice 'cannot be distilled to messages, story content or words, but must be opened up to the sustenance of sensation' (p.125); sensation that is relational, for it was the inter-relation between person and person, between people and their materials, and the care that was being taken to make the artwork together that affected me. Here, beauty was embedded within what Thompson calls 'the aesthetics of care' (2015, p.436), a process underpinned by the forging of 'interhuman relationships' (p.438) between project members. As Odeion expressed in his reflective session:

they keep everyone connected with the other

through what we did

what we made

for example

I am Algerian

my friend here

who is part of my family now

is Eritrean

we didn't speak the same language 
and we can't communicate with each other

but with the arts and workshops

the activities we used to do

we start to communicate with each other

even

just give me this

give me that

what is this

what is that

what's the idea

we start to understand each other

even different nationalities

different language

so its through the work

through doing the activities

the workshops

that is what connects us

These affective moments to me express what Thompson calls 'beautiful attentiveness' (2011, p.119) by creating hopeful ways of being together, moments 'to make visible a better world' (p.2). Indeed, Odeion's reflections prompt me to stress, with reference to Thompson, that participatory workshop spaces should not be considered as rehearsals for real-life, but real-life sites in and of themselves. Thus, I argue that through the purposeful acts of creative construction Share My Table worked to counter normative or even aggressive hegemonic tendencies by developing alternative ways of relating to 
one another, by 'stimulat[ing] affective solidarity between people' (Thompson, 2015, p.437).

\section{Visibility, Multiplicity and Responsibility}

Throughout Share My Table our artistic approach, in many ways, was an attempt to embed a radical pedagogy rooted in 'an ongoing recognition that everyone influences the classroom dynamic, that everyone contributes' (hooks, 1994, p.8). My artistic impetus was to create an environment where each individual's contributions were viewed as resources that could constructively enhance the capacity and creativity of the space we were building together (p.8). As project member Precise articulated it,

whether you can speak English

whether you cannot speak English

you want everybody to do something

that was very very good

there are other places you go to

they don't want to know

even if you sit there 24 hours

watching

everything going on

no one will come to you and say

what is your opinion

how do you see this

or what do you think we should do

I think

its a kind of like 
segregation

like

fine

your presence is welcome

but

we don't care about your opinion

and things like that

share my table wasn't like that at all

everybody had something to do

everybody was involved

One method Elena and I called upon to engender this engaged pedagogy was to develop a ritual for entering the creative sub-space as the workshop started proper. The ritual was to use a 'check-in', which saw the group gather in a circle and one by one share how they were feeling that day. Individuals were encouraged to experiment with their methods of communication-using English, using another language they were comfortable in, or using their bodies. Although often light-hearted, at moments the circle carried a profundity as people shared news of family reunification, loss of life and asylum process stress. These check-ins were supported by warmup exercises, that included work with the breath, physical movement and group interaction, all focused on creating space and time for each person to articulate themselves, even if all they wanted to say was 'hello'. Through our check-ins, the Studio established itself as a space that 'genuinely valu[ed] everyone's presence' (hooks, 1994, p.8).

Building on this commitment to valuing visibility for each person in the room, Elena and I built in time for creative sharings and moments of performance within each 
workshop. In her discussion on being part of a transformative pedagogy in multicultural spaces, hooks follows Paulo Friere in foregrounding the importance of building community, 'in order to create a climate of openness and intellectual rigour' (hooks, 1994, p.40). One way to do this 'is to recognize the value of each individual voice' (p.40) by sharing work with one another. It is the act of hearing a multiplicity of voices and listening deeply to one another-an act hooks terms as an 'exercise in recognition' - that each individual in the room is invited to 'make their presence known' (p.41). Share My Table embraced this approach and expanded upon this theory to consider not just the voice but the body as a source for making one's presence known.

We had a moment of all bodies moving together, of interweaving and negotiating themselves through the space. Then we asked them to do it one at a time-to keep the space alive-and to focus on each other. We managed to do this in silence, we started by all breathing together and then one by one they moved... There was a sense of risk taking-moving through any space can be difficult, but being actively witnessed is even harder. I felt I was watching Flower actually physically grow as she crossed the space-slowly taking pleasure in being witnessed. The group were holding the space for one another, they worked together and an atmosphere of mutual respect was palpable. It finished with an applause (Evans, 2017).

Whether we were reading or showing a piece of writing, exhibiting an art-work in one of our pop-up exhibitions, or expressing our emotional or intellectual ideas through tableaux, these intimate and fleeting sharings took on a multiplicity of meanings. They became a practice in and of themselves of inviting visibility-of normalising the 46 
process of being seen and heard as one's self. This process ran counter to the constant practices of categorisation (Crawley and Skleparis, 2017) that many of our project members were experiencing in everyday life. As Faith articulated 'every day we are refugees or asylum seekers to someone. Here we are ourselves'.

What emerged from inviting visibility was a growing consideration of the responsibility of the project member as viewer or the listener, and their role in creating a space where each was comfortable being seen and heard. By presenting these moments 'as a space to learn' not just about one another, but from one another, we embarked upon acts of 'collective listening' that affirmed 'the value and uniqueness of each voice' (hooks, 1994, p.84). In turn, we developed 'a communal awareness of the diversity of our experience' and so the sharings became a way for us to gain a better understanding of one another, as well as to deepen our understanding of how we inter-related with one another. I propose that through this we committed to 'a politics of the intimate' (Thompson, 2011, p.34), choosing to interpret aesthetics and beauty as process-orientated; 'as participants cocreating work, from their own desires, delights or inspiration' (p.159). In turn Share My Table resisted 'a communicative model of art' and became as much about developing a resistant politics of engagement that nourished those of us in the room, as it was about delivering a final 'impact, message or precise revelation' (p.125) to an audience. 


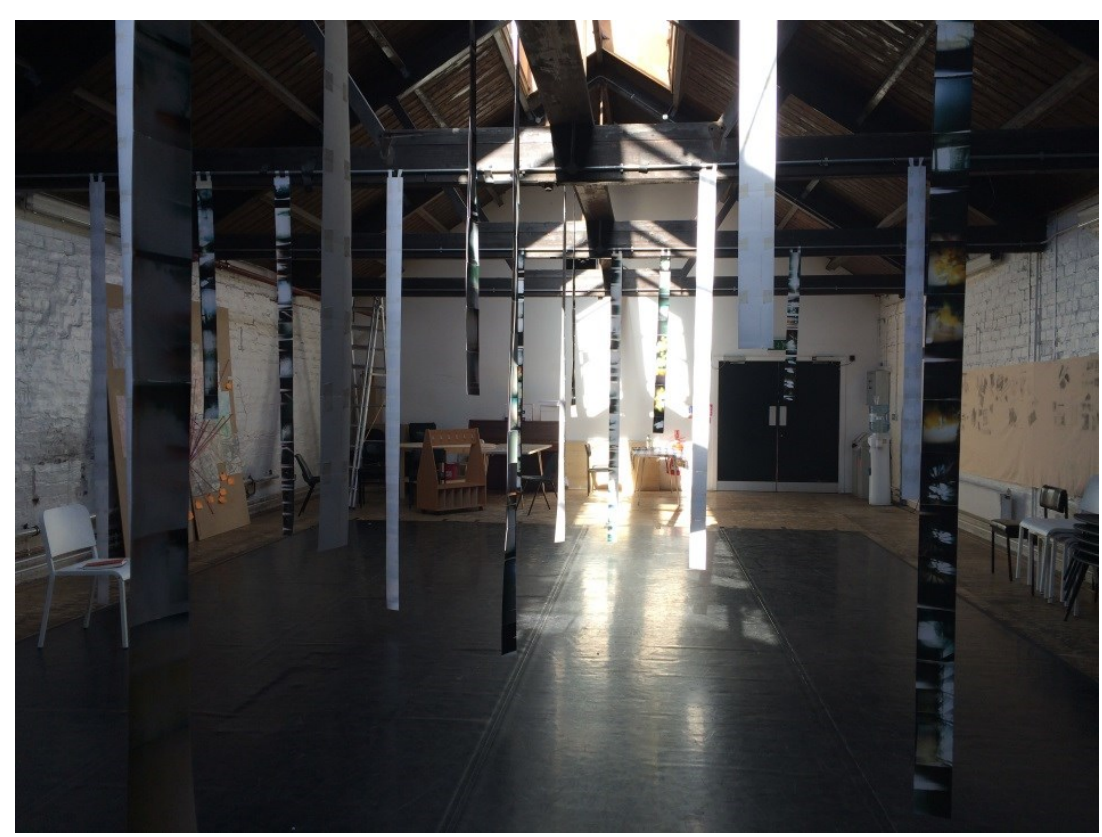

I see, I hear, I feel: using handmade pinhole cameras the project members captured abstract images of their everyday lives, then used the photographs as a starting point for new writing. Photo: Elena Mary Harris.

Finally, I want to highlight the importance of the workshop as space where multiple languages were spoken and utilised to share the creativity and ideas being developed. Whilst translation played a key role in enabling people to feel comfortable and able to access the space, the project tried to encourage a multilingual approach to art-making. Though many project members expressed their desire to use the project to improve their English and to communicate their ideas in English, the option of speaking in one's first, second or even fifth language was always encouraged and welcomed whenever anyone felt this was how they wanted or needed to speak. Phipps argues that

when asylum seekers use language, it is from places of extreme experience where language is subject to extraordinary pressure: pressure of legal narrative, pressure of traumatic recollection; pressure of pain and desperation, pressure in another language that is not their mother 
tongue; pressure to speak through tears (Phipps, 2012, p.587).

Our approach was to alleviate the burden of language from our creative space, allowing us to actively move away from the hegemony of an imposed monolingual culture. With up to ten languages in the space at any one time, this did not always mean that communication was easy. There were moments where we had to work through miscommunication, or where clashes of personalities and cultures required careful interventions. Furthermore, as a monolinguist myself I often felt embarrassed at not being able to remember words and phrases that were taught to me from week to week. Nonetheless, multilingual conversing offered us all the 'experience of hearing nonEnglish words' (hooks, 1994, p.172) and the opportunity to celebrate the richness of a diversity of phrases and sounds. Exactly by offering multilingual artmaking, Share My Table opposed 'a multicultural world that remains white supremacist' and that uses formal and bureaucratic English to disorientate and dehumanise as well 'as a weapon to silence and censor' (p.172). Advocating visibility, multilingualism and multiplicity within our space, became an act of resistance against the hostile environment outside.

\section{Conclusion: pushing beyond integration}

In this article, I have argued that arts practice can be read as a 'location of possibility'; a space focused on affective engagement 'where we have the opportunity to labor for freedom, an openness of mind and heart that allows us to face reality even as we collectively imagine ways to move beyond boundaries, to transgress' (hooks, 1994, p.207). I cautioned against the possible limitations of arts practice, whilst addressing how to create spaces that offer us alternative ways of being; artistic spaces that push against the hegemonic and hostile strategies that those navigating the asylum and immigration system face on a daily basis. Finally, I propose that arts practice, with a focus on the aesthetics of process, is a means through which we can challenge normative conceptions of 
integration. An aesthetics of process allows movement towards a more complicated and 'messy' understanding of community and society that is rooted in notions of interdependence, rather than integration. Danewid argues that global ethics and solidarity needs to be rethought so that connections are forged from 'the shared intertwined histories that arise out of the colonial past, and the neo-colonial present' rather than through the 'oneness and interconnectedness of humanity' (2017, p.1683). With regard to Danewid and Share My Table, I would welcome participatory arts practitioners moving away from the work of solely humanising or provoking empathy, whether it be between participants within a workshop or for audiences at a performance, and instead building artistic spaces where inter-relations and shared moments of creation and responsibility can form the basis for localised solidarity.

\section{Acknowledgements}

This research was supported by the Arts Humanities and Research Council as part of Evans's PhD inquiry. It was also supported by the Scottish Refugee Council.

I'd like to thank my supervisors Professor Alison Phipps, Dr Gareth Mulvey and Gary Christie, who provided insight and expertise that greatly assisted the research, as well as Tramway and Scottish Refugee Council for being open to my intention to undertake a practice-based approach through Share My Table.

I'd also like to thank Elena Mary Harris and Deborah May who made up the core delivery team with me for Share My Table, and who always encouraged me to bring my theoretical and critical self, as much as my practical self, to our work. I'd like to thank Najma Abukar for the beautiful photos she took of our work, and for her insights throughout this work. I'd also extend my thanks to Jo 
Walmsley and Holly Willoughby who went out of their way to ensure an ethical integrity to the project, as well as many staff members from both partner organisations whose support and expertise was so valuable throughout.

I would of course also like to thank all the Share My Table project members and volunteers whose creativity and insight, and whose patience with my ongoing attempts to capture their deepest reflections on the project was truly a gift.

\section{Notes}

1. As part of a process of maintaining ongoing consent from project members to feed into this research I invited everyone to choose their own pseudonym. All project member names used in this article were self-authored.

2. I would recommend Sarah Nuttall's introduction, as well as the individual essays in Beautiful ugly: African and diaspora aesthetics (2007). This offers an extensive insight into, and resists the Eurocentric definition of aesthetics and beauty defined by colonial, hierarchical 'unexamined whiteness'. [^]

\section{References}

Ahmed, S., 2010. Happy Objects. In: Gregg, M. and Seigworth, G., ed. 2010, The Affect Theory Reader, London: Duke University Press.

Bishop, C., 2012. Artificial Hells: Participatory Arts and the Politics of Spectatorship. London: Verso.

Crawley, H. and Skleparis, D., 2017. Refugees, migrants, neither, both: categorical fetishism and the politics of bounding in Europe's 'migration crisis'. Journal of Ethnic and Migration Studies, 44(1), pp.48-64.

Danewid, I., 2017. White innocence in the Black Mediterranean: hospitality and the erasure of history. Third World Quarterly, 38(7), pp.1674-1689.

Evans, C., 2017. Journal. Unpublished.

Heddon, D. and Johnson, D., 2016. It's All Allowed: The Performances of Adrian Howells. Bristol: Intellect.

hooks, b., 1994. Teaching to Transgress: Education as Practice of Freedom. London: Routledge. 
Ingold, T., 2011. Being Alive: Essays on Movement, Knowledge and Description. London: Routledge.

Jeffers, A., 2008. Refugees, Theatre and Crisis: Performing Global Identities. Hampshire: Palgrave Macmillan.

Jelinek, A., 2013. This is Not Art: Activism and Other 'Not-Art'. London: I.B Tauris \& Co Ltd.

McPherson, M., 2010. 'I Integrate, Therefore I Am': Contesting the Normalizing Discourse of Integrationism through Conversations with Refugee Women. Journal of Refugee Studies, 23(4), pp.546570 .

Mulvey, G., 2013. In Search of Normal: Refugee Integration in Scotland. Scottish Refugee Council Final Report.

Nuttall, S., 2006. Beautiful ugly: African and diaspora aesthetics. Durham: Duke University Press.

Phipps, A., 2012. Voicing Solidarity: Linguistic Hospitality and Poststructuralism in the Real World. Applied Linguistics, 33(5), pp.582-602.

Phipps, A., 2014. 'They are bombing now': 'Intercultural Dialogue' in times of conflict. Language and Intercultural Communication, 14(1), pp.108-124.

Salverson, J., 1999. Transgressive Storytelling or an Aesthetic of Injury: Performance, Pedagogy and Ethics. Theatre Research in Canada, 20(1) pp.34-51.

Scottish Government., 2013. New Scots Strategy: Integrating Refugees in Scotland's Communities, 2014-2017.

Scottish Refugee Council, 2017. Share My Table. [flyer].

Thompson, J., 2011. Performance Affects: applied theatre and the end of effect. Hampshire: Palgrave Macmillan.

Thompson, J., 2015. Towards an aesthetics of care. Research in Drama Education: The Journal of Applied Theatre and Performance, 20(4), pp.430-441.

Trimingham, M., 2002. A Methodology for Practice as Research. Studies in Theatre and Performance, 22(1), pp.54-60.

Vasta, E., 2010. The controllability of difference: Social cohesion and the new politics of solidarity. Ethnicities, 10(4), pp.503-521.

\section{About the author}

Catrin Evans is a theatre-maker, academic and activist. For the last twelve years she has been making work with Scotland's leading theatre companies. Work includes: I Hear The Image Moving (Tramway / Scottish Refugee Council), To Hell and Back (Oran Mor), Endurance (A Moment's Peace), Dear Scotland (National Theatre of Scotland), Leaving Planet Earth (Grid Iron / Edinburgh International Festival); Some Other Mother by AJ Taudevin, The 
Sweet Silver Song of the Lark by Molly Taylor (Oran Mor) and Thank You (Oran Mor), The Chronicles of Irania (A Moment's Peace).

Catrin is the Artistic Director of A Moment's Peace Theatre Company, whose reputation for delivering innovative participatory arts projects across Scotland marks them out as an integral part of the socially-engaged arts community. Catrin has a history of creating work focused on refugee and asylum issues and is committed to developing the relationship between arts and activism in order to resist structural and cultural inequalities. As well as her work with AMP and as a freelance artist, Catrin is undertaking an AHRC-funded practice-based PhD at the University of Glasgow, in partnership with the Scottish Refugee Council and Glasgow Refugee Asylum and Migration Network. 
Scottish Journal of Performance

Volume 6, Issue 1 
PRACTITIONER REPORT:

\title{
'Where are you from? A woman's body': Navigating notions of belonging through poetry and playwriting with refugees and asylum seekers
}

\author{
HELENE GRØN
}

DOI: $10.14439 /$ sjop.2019.0601.04

Publication date: 14 July 2019

This article reflects on the complicated entanglements of belonging in encounters between asylum seekers or refugees with citizens of a shared country. Using the question 'where are you from?' as a key to discussing what is at stake in these meetings, the following takes seriously the idea that we come into being also through the meeting with one another, both as nations and individuals. These encounters operate within a larger production of media and political narratives of hostility, making belonging at the very least politically a contested idea in a refugee's life. Drawing in the voices and experiences from two separate contexts and fieldworks of writing plays and poetry with groups of refugees and asylum seekers (a women's group in Glasgow and a group living in a deportation centre near Copenhagen), my practice seeks to demonstrate the capacity of theatre to navigate these complex and entwined perceptions of belonging.

Keywords: practice-as-research, asylum, belonging, refugee, playwriting 
where are you from?

here

where are you from?

the sky

where are you from?

the moon

where are you from?

the sun

where are you from?

you, you, you

where are you from?

afghanistan

where are you from?

afghanistan

where are you from?

afghanistan

(Sareh ${ }^{1}$, Youth Community Support Agency, 2018).

\section{Introduction}

Why should there be a difficulty in asking someone 'where are you from?', and how does this dynamic change when the conversation happens between a citizen of a 
country and a refugee whose situation of belonging may be precarious? Can daily interactions such as these make or unmake senses of belonging? And how does poetry and playwriting create a different space around these conversations?

I offer these questions as a preamble to reflect the complications in navigating notions of belonging in the two fieldworks this article centres around: one with the Women's Group from the Youth Support Community Agency (YCSA) in Glasgow, a multicultural group of women from refugee, asylum seeker and migrant backgrounds; the other with a group of rejected asylum seekers living in Deportation Centre Sjælsmark northwest of Copenhagen who were all users of Trampoline House ${ }^{2}$. Although radically different contexts, the question of 'where are you from?' was a recurring and central component reflecting the complicated and refracted notions of belonging.

It is crucial to note the difference in the fieldworks from the outset. The YCSA group live in accommodation in and around Glasgow, go to college to learn English and are in various stages of the asylum process. The group in Sjælsmark are all rejected asylum seekers waiting to be sent back to their home-country, or the country they were fingerprinted in under the EU's 'Dublin Regulation'. However, it is impossible for many of them either to stay or to leave: because their home countries will not collaborate with the Danish government; because it would be too dangerous for them to return; or because the conditions for asylum seekers in the countries they have fingerprinted in are worse than Denmark.

Both fieldworks were centered around the process of creating a play about how the question of home and belonging arose and manifested in their lives: with the YCSA the play became This Is Amelia / We Are All Amelias, a heartfelt reimagining of the story of Amelia 
Earhart set against the realities of living with and fleeing from conflict. The group in Sjælsmark wrote the play This Is Us, a story of two politicians in an ideological battle over asylum laws, interspersed with scenes and monologues reflecting the daily realities of living in a deportation centre and the struggles of being seen first and foremost as a refugee. In both of the creative processes the groups spent time on dramaturgy and unpicking the workings of plot and stories, as a way to hand over the writing process to them, and to understand the stories constructed around their identities and legal situations of being refugees and asylum seekers by media and political rhetorics.

Taking the difficulty of asking 'where are you from?' as a key to discussing the responsibilities of belonging in everyday encounters and conversations came from poems written by the women from YCSA; four of which open each section of this article, and one of which I take my title from (see Asma's poem). The YCSA facilitated several creative workshops with the group. As part of a sharing of these outcomes, they took part in a poetry workshop and evening sharing at The Scottish Poetry Library in March 2018. The workshop was facilitated by poet Hannah Lavery. In the session, Hannah asked them to name the questions they found it annoying to be asked. These were: 'where are you from?', 'how did you arrive?' and 'why are you here?' Based on this the group wrote poems responding in the ways they wished they could in the everyday conversations and encounters where such questions arose. At the 2018 UNESCO Spring School in Glasgow I presented a paper on the poems exploring whether, in encounters between citizens and asylum seekers or refugees, the questions in the women's poems could be considered uprooting and destabilising to senses of belonging. In the Q\&A session following the paper the audience expressed conflicting opinions on the issue: some felt that 'where are you from?' should not be discarded as a harmless conversation starter coming from compassionate desire to know a person more deeply; others reported questioning their belonging to current 
contexts when asked; some expressed the inability to account fully for a life lived with complicated geographical origins or precarious belongings in such conversations.

This is not to discard the question 'where are you from?' as a harmless conversation starter or to assume the fragility of the person being asked. Rather, I wish to suggest that there might be more at stake in these conversation starters than first imagined. Instead of presenting a case for the question being either fully harmful or fully harmless, it is perhaps more productive to use it as a backdrop for discussing the difficulty of belonging and the ethical responsibilities and challenges surrounding how we interact with each other when we are in different situations of belonging. The women's poetry and three scenes from the two plays written with the groups will form the basis of this article's exploration of how poetry and playwriting opens up the conversation in a different way.

There are several unsettlings at play in this. Creating work (both research or creative) that seeks to be decolonising, done, in my case, from the scholarly and artistic perspective of a white female who benefits from citizenship of one European country and residency in another is, and should be, uncomfortable. This does not mean that the work should not be attempted regardless, but it does, perhaps, mean letting the voices of lived experience take precedence over more theoretical ones. Secondly, problematising everyday conversations where questions like 'where are you from?' demands unsettling: the unsettling that the ways we speak and meet each other is part of a larger social and political framework, and the unsettling that we can misunderstand each other regardless of intentions. I would therefore like to take seriously the Danish philosopher and theologian K.E. Løgstrup's idea that: 'Den enkelte har aldrig med et andet menneske at gøre uden at han holder noget af dets liv i sin hånd-one never has anything to do with another 
person without holding a part of their life in one's hand' (My translation, Løgstrup, 2012, p.25) as a framework to speak about how we come into existence in the meeting of the other, and how these encounters carry the potential for making or unmaking senses of belonging.

\section{Person $=$ Country}

why are you here?

to explore

why are you here?

to show the world what i have

why are you here?

it is a right to be here

why are you here?

relax

why are you here?

am i not allowed here?

why are you here?

fly

why are you here?

high

(Fatma M, YCSA, 2018). 
In a sense, the tone is already structured around encounters where belonging is at stake. The idea of belonging itself is bound up in social structures of opportunity, privilege and nationality: belonging is even formulated around us by a larger production of media and political narratives formulating who belongs and who does not. In the wake of the so-called refugee crisis, recent years have seen an increasing 'narrative of crisis' (Ahmed, 2004, p.132). The overarching story about asylum seekers is 'a single, virtually uninterrupted message of hostility and rejection' (Cohen cited in Jeffers, 2012, p.25) constructing 'those who are "without home" as the "source of our [the receiving countries and their populations'] fear"' (Ahmed, 2004, p.136). Added to this are the images portraying bombed cities and precarious journeys across land and seas by those seeking safety from conflicts in their home countries. All of these narratives and framings, combined with the loss of home countries, means that belonging is, at the very least politically (and I would suggest also existentially) a contested idea in a refugee and asylum seeker's life.

Asylum seekers are also asked to account for their 'from' in many ways outside everyday conversations. When seeking asylum, they must:

convince the authorities that they have a clear and credible story which demonstrates the individual past persecution in their own country [...] This must be couched in the terminology of international law so that it is recognised as operating within the boundaries of the 1951 UN Convention [...] But the story alone is not enough and it must be rehearsed to create a credible performance, convincing in the telling as well as the construction (Jeffers, 2012, p.30). 
Seen in this light, 'where are you from?' is part of a system of nationalistic and formalistic belonging that asylum seekers have to operate within. The story told to authorities has to be not only credible, but also performed with credibility before the project of belonging to a new country and context can even begin. All of these factors 'makes that figure [the asylum seeker] do more work' (Ahmed, 2004, p.122). Indeed, the work of integration, of belonging and of convincing authorities that, according to conventions and in line with bureaucratic languages, they have the right to belong. However, between the way a country, an asylum system and the media treat them this process can be extremely complicated as '[v]ery few people have the strength to conserve their own integrity if their social, political and legal status is completely confused' (Arendt, 1996, p.116). Indeed, 'we lose confidence in ourselves if society does not approve of us' (p.119).

In terms of these factors having an effect on everyday conversations of belonging, Daniel, a refugee from Iran and a user of Trampoline House, said: 'whenever I open the TV or newspapers, all of the media here [referring to Denmark], most of them are against refugees' (Daniel, interview with the author, 14th December 2018). When I asked him how he felt when people in Denmark asked him where he is from, he answered: 'it's one of the most difficult questions for me to answer. I'm thinking maybe they asked this question because they feel I don't belong to their country and I should go back'.

In the first workshop with the group in Sjælsmark, I asked them to write or draw all the things that made them feel like they do not belong. One of them wrote 'person $=$ country'. He told me that whenever he was defined by or equated with his country, or categorised as being an asylum seeker before being seen a person, he felt like he did not belong. When the question arose again people in the group expressed the same frustration of being categorised as a refugee and being defined only in 
terms of nationality by the media and the Danish people they met in their daily lives. They made clear that their nationalities and the way they had journeyed to Denmark (perhaps having been fingerprinted in another country) formed the basis of why they had been rejected as asylum seekers, and thus why they were not allowed to belong.

Sjælsmark is an old army barrack located behind a fence and approved as a deportation centre by political majority in 2015. It is considered a last stop in Denmark and the conditions in the centre are designed to signify to the residents that they are no longer welcome and should return to their countries. It is difficult to get to and from the camp via public transport and only very few of the residents get subsidies from the government; they are not allowed to cook their own food but have to eat in the cafeteria at three set times a day. If they want to stay with friends and family, they must apply for this weeks in advance. Their keys log when they exit and enter, and there is close to no privacy. Larger families share a very small flat while single people share bunk bed rooms with other residents (Hergel, 2017). In public debates, Sjælsmark has often been compared to a prison and the daily running of the centre is carried out by Kriminalforsorgen (the segment of the Danish social system that also operate Danish prisons). Life in the camp sends the clear message that the asylum seekers are not welcome in Denmark and that they are seen as criminals, disregarding the fact they have committed no crime, unless fleeing unsafe situations in their home countries could be considered one.

The group's daily lives were dominated by this lack of liberties, agencies and repeated contact with systems that denote they do not belong in Denmark. They told me that because of these experiences, when someone asked them where they were from, they often answered with 'good European countries' (France, Italy or Spain), rather than their actual nationalities (Syria, Lebanon, Iran) simply to avoid being categorised or seen in a certain way, or 
because they had experienced that people made excuses to leave the conversation if they answered with their actual nationalities. The fact that people were often prejudiced against them because of their nationality meant they had learned to lie in order to avoid what seemed like the inevitable conclusion of such encounters.

When interviewing the women from YCSA I asked Asma what made her feel not-at-home:

Asma: Sometimes you get people just out of nowhere asking you weird questions. That makes me a little bit feel out of place. Like those questions that we answered at the poetry [referring to Hannah Lavery's workshop]. That kind of makes you feel like this is not your place.

Helene: Because of the people who ask or because of the questions?

Asma: The questions. That kind of shakes my comfortability of being here.

(Asma, YCSA, Interview on 28th May 2018).

As Asma expressed, it was not necessarily that the people who asked her did not mean well, it was the questions themselves that shook her comfort and belief in not only belonging, but being in Glasgow. Thereby showing that regardless of intentions, the questions themselves had an impact on the way she understood herself as part of the country she inhabits, perhaps and most likely because of her experiences with a society predominantly not approving of asylum seekers and refugees. Thus showing that the space around the questions is already one that carries the remnants or echoes of the larger media and political production of hostile narratives. 


\section{Doing the work of belonging together}

how did you arrive?

ocean

how did you arrive?

water

how did you arrive?

air

how did you arrive?

fly

how did you arrive?

how?

how did you arrive?

here?

how did you arrive?

any problem?

how did you arrive?

don't worry

how did you arrive?

nae bother.

(Fatma A, YCSA, 2018). 
Central to the question of belonging is that of hospitality and of being politically and ethically implicated, both as nations and individuals, in our encounters with each other. There is significant scholarship on hospitality (Still and Derrida, 2013; Levinas, 2013; Irigaray, 2008; Cixous, 2014), and while a deeper exploration of the notions and complications (including the power relations of who gives and who receives, who is constructed as the host and who is constructed as the guest or the stranger) goes beyond the framework of this article, there are relevant points to be made by using the term.

First, the notion of hospitality offers a framework for taking into account the increasing amount of thought being given to the fact that the so-called refugee crisis is more about European countries' national identity and struggle to adhere to conventions than it is about the refugees themselves (Weiwei, 2018; Jeffers, 2012; Arendt, 1973). Indeed, 'the treatment of refugees can be taken as a kind of ethical measure with which to assess the degree of hospitality or largesse shown by a nation towards the stranger' (Jeffers, 2012, p.6). While there is, evidently, a difference between relating on individual levels versus national ones, the building-blocks of ethics in the realm of hospitality become apparent in exactly this relationshipas Derrida has said, 'ethics is hospitality; ethics is so thoroughly co-extensive with the experience of hospitality' (cited in Still, 2013, p.7). Living with and among people who come from the countries affected by war and conflicts makes it increasingly urgent to consider the meeting of the other as 'the venue for [...] ethical responsibility' (Butler, 2005, p.22) and what we are called to do with this responsibility. One suggestion could be to purposefully address the structural imbalances, as Simone Weil suggests: '[i]f we know in what way society is unbalanced, we must do what we can to add weight to the light scale' (Weil, 2008, p.171). However, by extension it could also be necessary to contemplate whether it is about more than hospitality or hostility, about more than citizens or countries opening or closing their doors to those arriving. For example, if '[t]he 
presence of migrant, forced or otherwise, offers an opportunity to re-define all identities as ethically produced' (Jeffers, 2012, p.10), then the redefinition of this would involve a closer look not only at the political and national structures of belonging, but also at those who are in the position of offering this hospitality and welcome.

Secondly, hospitality is above all 'an everyday experience' (Still, 2013, p.1). Therefore, to bring this into a more concrete realm, refugee minister Niels Nymann Eriksen turns around Løgstrup's thought of holding a part of the another's life in our hand (2012, p.25). In his work in the multicultural area of Vesterbro in Copenhagen, Eriksen has encountered the opposite idea; namely, that in meeting the other (in this case, specifically asylum seekers and refugees), they are the ones holding something of his life in their hands (Eriksen, 2018). Turning this around shows that however unsettling, however complicated, there is a radical need to allow not only being held but also changed by another, both as nations and as individuals. Indeed, as Luce Irigaray notes, it is exactly in opening up from within that the challenge of hospitality lies: '[t]o open a place for the other, for a world different from ours, from inside of our own tradition, is the first and most difficult multicultural gesture' (2008, p.133). Hospitality (and by extension belonging) in this sense shifts from being something citizens of a country may choose to do or not to do to the people arriving from other places into something that could be a mutual project. In that case it becomes not about welcoming other people into a culture that already exists, but rather exploring the possibility of how we can create new and shared cultures of belonging together.

\section{A Woman's Body}

where are you from?

home 


\author{
where are you from? \\ because I'm black? \\ where are you from? \\ relax \\ where are you from? \\ a woman's body
}

(Asma, YCSA, 2018).

Neither theatrical nor poetic space are uncomplicated; both are implicated in structures and histories of power that have prioritised certain positions and stories over others. It is necessary to remain critical, as James Thompson is, of the idea that a theatrical project dealing with politics through subject matter or people involved, is 'by some default process [...] one that can claim an automatic contribution to social change' (2009, p.5). Indeed, centering theatrical performances around people's life experiences can lead, in Clare Bishop's words, to people merely reinforcing and performing 'their own socio-economic category' (as cited in Mumford and Garde, 2015, p.9) without subjecting it to critique and examination. This line of questioning is essential to theatrical and poetic space involving both subject matter and subject positions around refugeedom. However, there is also the notion of artistic space and practice having the ability to present counter-narratives set against a sociopolitical framework of hostility. For example, Mieke Bal's concept of 'migratory aesthetics' offers an 'ethical imperative to provide a congenial, friendly soundscape in which mobility-the migratory-is not the despised exception but the valued norm' (2007, p.33). And Derrida offers that: '[a]n act of hospitality can only be poetic' (2000, p.2). In this view arts practice can open up 'a counter-reality [...] which may be only imagined, but 
which nevertheless has weight because it is imagined within the gravitational pull of the actual' (Heaney, 1996, p.18). Exactly because of its relation to the actual, poetry in this context can extend the notion of belonging beyond being categorised as a refugee; it can use the experiences of conflicts of belonging and accounting for a 'from' for something other than 'bureaucratic performances' (Jeffers, 2012, p.16). Furthermore, both poetry and playwriting work with the creation of images through and, indeed, beyond words. Poetic and theatrical images can 'express without formulating' (Walter Benjamin cited in Stevenson, 2014, p.15) and they 'are useful precisely because they can capture uncertainty and contradiction without having to resolve it' (p.13).

The women's poems (see the cited poems by Sareh, Fatma and Asma) make clear to the reader the conversational realities they have been exposed to when having to account for their 'from', and make them think of alternative ways of answering and of belonging. The poetic space that these answers occupy is different and perhaps richer than geographical location as it can speak to a space of shared experience. For example, answering 'where are you from?' with 'home' or 'a woman's body' speaks to a universality, to a place beyond location where we are all alike, as we are all from 'home', all from 'a woman's body'. Notably, the majority of the women in the group are from countries and situations that are hostile to women, where it is hard to be a woman, to have a woman's body. Asma's poem uses this as a point of defiance and of unity; being from and of a woman's body is what allows everyone to be in the world, the human experience of 'from' without which nobody would exist. 'Where are you from? / you' speaks to the ways we belong to each other, and, 'the sun', 'the moon' states how we belong on earth as human beings, being grounded by the cosmic and relational realities of our lives on earth: night, day, heat, cold, relationships, community. 
Theatre adds a spatial component and perhaps a more immediate relation to the world if we think of performance also as 'vulnerable and open to dialogue with the world' (Conquergood, 1985, p.2). It can, in Avtar Brah's words, hold the potential for 'diaspora space [where] multiple and subject positions are juxtaposed, contested, proclaimed or disavowed' in a space that 'is small enough to examine moments of encounter; the space between two individuals on stage' (cited in Jeffers, 2012, pp.10-11).

As mentioned above, in writing their play, the YCSA women's group chose to work re-work the story of Amelia Earhart into their play. In their story, Amelia is from a world where she does not belong; she wants to be a pilot, but women are (among other things) not allowed to fly in her country. She goes to explore three different countries to find a place where she can be her true self, as a woman, as a pilot, as a person in the world. After leaving the first country, Lemon Island, a place where she must be under male supervision at all times, she ends up in a bus going to Nowhere. In this scene the women used some of their lines of poetry to show Amelia as a displaced stranger arousing the curiosity of her fellow passengers who want to know her geographical origin:

Passenger: Where are you from?

Amelia: A place that buried my hopes and dreams.

$[\ldots]$

Passenger: Where are you from?

Amelia: Oh for goodness sake.

Passenger: But where are you from?

Amelia: Here. 
Passenger: But where are you really from?

Amelia: A woman's body.

Passenger: Why are you here?

Amelia: To see the unseen and share the stories.

Passenger: Where are you going?

Amelia: On a journey that's worthy.

On and on she goes, answering questions nobody should be asked, reminding her only that she's not home anymore and she doesn't yet belong where she's going.

$[\ldots]$

Amelia. Please, just nobody ask me anything anymore. I'm nobody from nowhere, okay.

(Youth Support Community Agency, 2018, excerpt from Scene 3).

Transforming the poems into lines for a play restructures the situation. It takes it out from the imagistic realm of poetry and makes clear the situation and the frustration of meeting such questions when one is on a journey of belonging. Amelia's exasperation shows in the last line ('nobody from nowhere'), giving up on being known and satisfying the too curious passengers who are not content with being answered in poetry.

Later Amelia makes a narrow escape from Nowhere, a country where a war is raging yet nobody can remember exactly why the war started or what they are fighting for. 
She is caught by the authorities, identified as a foreigner and sent to a detention centre. In the car with other refugees, she addresses the question of belonging:

Amelia looks at everyone who's travelling with her.

She wonders about their faces and their lives.

Amelia: Where are we going?

Person: We're being sent to Detention.

Amelia: Why?

Person: Don't know. I guess nobody wants to deal with us. Why are you here?

Amelia: I'm trying to find a country I can belong to.

People: Aren't we all?

Amelia: Where do you belong?

People: We don't belong anywhere.

Amelia: That's not true.

People: Yes it is.

Amelia: No, we belong to every drop of joy, we belong to Hope, we belong to Love.

Person: Life isn't like that.

(Youth Support Community Agency, 2018, excerpt from Scene 5). 
The situation in the car draws on the realities and risks that asylum seekers face of being sent to detention. The scene tackles both the reality of the situation ('I guess nobody wants to deal with us') and the poetic potential of belonging to other things than nations and geographical locations ('We belong to every drop of joy, we belong to Hope, we belong to Love'). The writing thereby works on two levels; both speaking a poetic and alternative conversation into hostile places of non-belonging as well as unlocking the creative possibilities of allowing something different to emerge from those experiences.

Choosing Amelia Earhart's story as a backdrop and collectively writing from the existing poetry and the group's individual stories provided the opportunity to draw from a rich patchwork of fiction, biography and creative approaches to belonging through storytelling and poetry. The obstacles Amelia encounters were ones some of the women encountered in their lives. The hostile places Amelia is in: the car with refugees, detention centres, places where it is hard to be a woman-all drew on experiences of the group.

Much like the real Amelia Earhart's life, the story ends unresolved. After gaining access to her own aeroplane, Amelia in the women's story flies over the Atlantic. Her quest has not been achieved and so she journeys on, yet to find a place that feels like home. Leaving Amelia in this in-between stage where she might (as the real Amelia did) disappear never to be found again or might yet find her home, shows the complications of belonging in the refugee situation: the ongoing story, the continuing journey of exploring the spaces-poetic or real-to belong.

One of the scenes punctuating the main story of the two politicians in This Is Us by the group at Deportation Centre Sjælsmark drew directly on the 
experience mentioned above of answering different 'good European countries' when people asked them where they were from:

A refugee, a mormon and a politician walk into a bar.

Just joking.

No seriously, so one day I walked past a bar, out in front smoking was this beautiful girl, and I wanted to talk to her.

Now I have a survival tactic for situations like these. In my pocket at all times, I have this paper. It's a plan, it is very important to me, what it is, a paper of Denmark cities in one column, and on the other column, it is matched with european and good countries to tell girls that I'm from so they don't freak out. Imagine-'hey, where are you from?' 'Syria'She'd be out of there. So I checked what city I'm in, and what's the matched country on the other side. So for example: Allerød = Italy. And it works every time, except for this one time.

He goes and ask someone from the audience that they agreed before.

Nicholas. Hi

Girl. Hey

Nicholas. My name Nicolas

Girl. Hi Nicolas, my name is Anne. Where are you from?

Nicolas. (He checks the paper). I'm from France, and you?

Anne. I'm Danish, born and raised. 
Nicolas. I saw you from away, and you got my attention. Can we get to know each other?

Anne. Sure. I saw you too.

Nicolas. Cool! can I have your phone number?

Anne. Yes absolutely. Can I have your phone to put the number in?

Nicolas. (To the audience) See?

Nicolas hands her the phone, and then his friend comes to him and speaks in Arabic.

Friend (in Arabic). Hey you, will you introduce me?

Nicolas get nervous and tries to push him away and speaks in french.

Nicolas. Degage! Go away! pas maintenant.

Anne. Who's that? what did he say?

Nicolas. (in english to Anne). No idea, clearly he's crazy. (In French to his friend) Go away.

Friend. (In Arabic) What are you doing?

Anne. Seems like he knows you. (To the friend) Do you know him?

Friend. I'm his friend, we know each back in Syria.

Nicholas. (In Arabic) Please stop.

Friend. We were just speaking Arabic.

Anne. Arabic? From Syria?

Nicolas tries to stop him from speaking, arguing and pushing his friend in Arabic. Then 
Anne hands him his phone back, without giving the number.

Anne. Hey sorry, my mom called me an hour ago, I have to see my friends back home. Pleasure meeting you.

So I walk on. And 20 minutes later Anne is sitting with an Italian guy, and not like an 'Allerød = Italy guy'3, a real wine, spaghetti, pizza Italian one.

(Trampoline House, 2018, excerpt from Scene 7).

This scenes thinks humour into a situation the group had identified as times where they questioned their senses of belonging. However, the scene does not seek to resolve the situation. Neither Nicholas's nor Anne's positions change, speaking to the structural challenges they both operate within; he, as a refugee, she as a 'Danish, born and raised' citizen who, for unspecified reasons, chooses to leave once she learns Nicholas is from Syria. In this situation, much like in the group's own lives, being part of the story does not change anything; rather it shows the conflicts of the encounter. Anne is unable to make him welcome, or to sustain her interest in him once she learns where he is really from; he is, ultimately, unable to hide it even if he plays the role of a person who is accepted in the situation they share. These two positions exist alongside each other even if there is not an easy or immediate solution to the problems of belonging between them.

Although neither Amazing Amelia / We Are All Amelias, This Is Us, or the YCSA women's poems solve the problems of belonging faced in refugee situations or encounters that carry the question of 'where are you 
from?', they do offer a space of holding contradictions together-showing the stakes and precarities with which belonging is made and unmade. It is perhaps exactly in this resistance to an immediate or easy solution that the positions become clear and the space of poetry and theatre enter as a possible way of unfolding the question of belonging outside and beyond the narratives produced by socio-political and nationalistic systems of belonging.

\section{Acknowledgements}

A thank you to the many people who contributed their time, talents and stories to create the plays and this piece of research.

To the Youth Community Support Agency, Clare MacBrien, Hannah Lavery, Fariha. The amazing sistas, Amelias, poets, singers, playwrights, actors: Asma, Fatma A, Fatma M, Nuha, Alhan, Christianah, Olda, Sareh, Shobhita, Vane Nana. Thank you for teaching me oceans of meaning about courage, belonging and joy.

To Trampoline House for being a place of dignity and belonging to many. To the writers, drawers, actors, participants from Sjolsmark Deportation Centre: Abbas, Rohan, Ghafour, Payman, Ahmet Kaya, Van Damme, Hasan, Salam, Andrew, Claudia, Badr, Azad, Mey. Thank you for joining the process, for being generous with your stories, for teaching me everything from the beauty and problems of the places you were born to the need for real structural change, deep engagement and development of fairer systems. 


\section{Notes}

1. Some of the participants in this research have chosen to use pseudonyms while others preferred their given first names. These are not distinguished in the body of the article. ${ }^{\uparrow \uparrow}$

2. Trampoline House is a community house for refugees and asylum seekers in Copenhagen. $\stackrel{\uparrow}{\uparrow}$

3. Allerød is a town located very close to Sjælsmark. ${ }^{[\uparrow]}$

\section{References}

Ahmed, S., 2004. Affective economies. Social Text, 79(22), pp.117-139.

Arendt, H. and Robinson, M., 1996. We refugees. In: Altogether Elsewhere: Writers on Exile. San Diego, CA: Harcourt Brace, pp.111-119.

Arendt, H., 1973. The origins of totalitarianism. San Diego, CA: Harcourt Brace Jovanovich.

Bal, M., 2007. Lost in space, lost in the library. In: S. Durrant and C.M. Lord, eds. Essays in Migratory Aesthetics: Cultural Practices Between Migration and Art-making. Amsterdam, Netherlands: Rodopi, pp.23-37.

Butler, J., 2005. Giving an account of oneself. New York: Fordham University Press.

Conquergood, D., 1985. Performing as a moral act: ethical dimensions of the ethnography of performance. Literature in Performance, 5(2), pp.1-13.

Conquergood, D., 1991. Rethinking ethnography: towards a critical cultural politics. Communications Monographs, 58(2), pp.179-194.

Derrida, J. and Dufourmantelle, A., 2000. Of hospitality.

California, CA: Stanford University Press.

Eriksen, N.N., 2018. Gostfrihed. [online] Available at: , $<$ www.facebook.com/akademiskforlagegmont/videos/202191535 4521667/> [Accessed: 22 December 2018].

Heaney, S., 1996. The redress of poetry. New York: Farrar, Straus and Giroux.

Hergel, O., Børns Vilkår: Forholdene på Sjælsmark er kummerlige. Politkken, 29 Oct. 2017, $<$ www.politiken.dk/indland/art6180917/Forholdene-påSjælsmark-er-kummerlige> [Accessed 22nd December 2018]. 
Irigaray, L., 2008. Sharing the world: from intimate to global relations. London: Bloomsbury.

Jeffers, A., 2012. Refugees, theatre and crisis: performing global identities. Basingstoke: Palgrave Macmillan.

Levinas, E., 2013. Totality and infinity: an essay on exteriority. Pittsburgh, PA: Duquesne University Press.

Løgstrup, K.E., 2012. Den etiske fordring. Aarhus: Klim.

Mairéad, H., 2014. Cixous's semi-fictions: thinking at the borders of fiction. Edinburgh: Edinburgh University Press.

Mumford, M. and Garde, U., 2015. Staging real people: on the arts and effects of non-professional theatre performers. Performance Paradigm: A Journal of Performance and Contemporary Culture, 11, pp.5-15.

Stevenson, L., 2014. Life beside itself: imagining care in the Canadian Arctic. California, CA: University of California Press.

Still, J., 2013. Derrida and hospitality: theory and practice. Edinburgh: Edinburgh University Press.

Thompson, J., 2009. Performance affects: applied theatre and the end of effect. Basingstoke: Palgrave Macmillan.

Trampoline House, 2018. This Is Us. Unpublished.

Weil, S., 2008. Gravity and grace. London: Routledge.

Weiwei, Ai, 2018. The refugee crisis isn't about refugees. It's about us. [online] Available at:

$<$ www.theguardian.com/commentisfree/2018/feb/02/refugeecrisis-human-flow-ai-weiweichina?fbclid=IwAR27OzCGkog5F94kBnt2a7E09Qo15AKyE0exO UATXL8JXIYvjz9inIdDaVs> [Accessed 22 December 2018].

Youth Support Community Agency, 2018. Amazing Amelia / We Are All Amelias. Unpublished.

\section{About the author}

Helene Grøn, AHRC funded PhD candidate in Theatre Studies at the University of Glasgow and Glasgow Refugee, Asylum and Migration Network (GRAMNet).

Helene is a Danish playwright, librettist, facilitator and researcher, currently residing in Glasgow. Helene co-founded the theatre company Leylines, bringing to the stage stories of home, homelessness and being caught between languages and cultures and has written librettos and operas for Scottish Opera, The Night With... and Cottiers' Chamber Project; her plays have had readings 
and been performed at The Traverse Theatre in Edinburgh, The Arches in Glasgow, The Scottish Storytelling Centre and at The Copenhagen Theatre Circle. She has facilitated creative community projects with refugees and asylum seekers for Kaleidoscope, YCSA, Trampoline House and Detention Centre, and frequently works in the intersection between research, political engagement and arts practice. 


\section{Performance review: -ish, by Aby Watson}

\section{LUCY HOLLINGWORTH}

DOI: 10.14439/sjop.2019.0601.05

Publication date: 14 July 2019

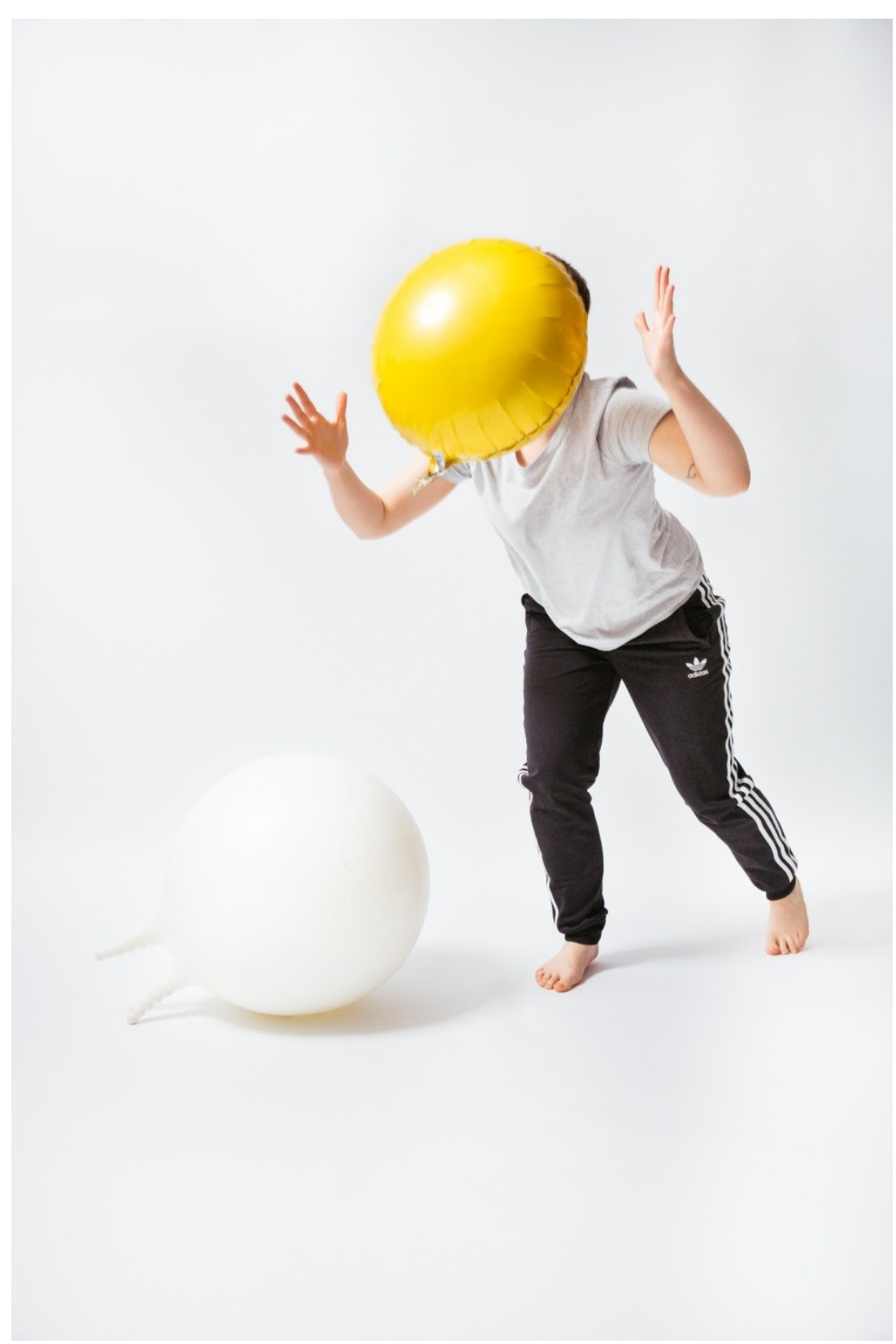

Photo: Jassy Earl Photography. 
Start up suddenly, jump, rotate the arms, run, stop, lean into the wind, reach for the sky, collapse, roll, bounce. Aby Watson's -ish is a dance performance and part of her research programme Choreographing Clumsy: Dyspraxia and Choreographic Practice ${ }^{1}$. Watson is a dancer with dyspraxia, a neurodiverse condition affecting coordination and cognitive processing. Her project seeks to find a practice that creates space for 'clumsy' behaviours in dance and to generate a model which does not treat dyspraxic movement as a deficit, but as a source of creative inspiration and energy.

I saw -ish on Tuesday 20 October 2018, the second of two performances at Tramway's Unlimited festival in Glasgow. It was exhilarating and exhausting to watch. Watson has a knack of taking her audience with her and allowing them to feel as she feels. Using simple props such as a fan, helium balloons, and a space hopper (which was pumped up by an audience member during the performance), she explored the space in the studio in what appeared to be free and liberating improvised short dance sequences. They were never chaotic, however, and I suspect that the freedom was generated by a tightly conceived scheme allowing small elements to contribute to the creation of a larger preconceived narrative. The performance was punctuated by moments of stillness, such as a period of collapse onto the ground when Watson showed us how it felt to have used up every resource.

The dance sequences were prefaced by word pairings (projected onto the wall behind the performance space): rising / falling, silent / loud, able / unable, mind / body, steady / wobbly, order / chaos. These gave the audience a handle on what was to follow. They represented the contradictions in the freedom and structure of each sequence, and also the contradiction inherent in the concept of a choreography for a dyspraxic performer. I was particularly intrigued by the performance of gymnastic forward rolls over the space hopper as creative expression. As the sequence developed I found myself drawn into the patterns created in my memory as Watson found every possible way and direction for such a simple 
gymnastic form. The unspoken statement was 'this is what I can do' and 'this is how creative I can be', despite the risks of random exit from each roll to an unexpected place on the floor. Recalling my own experiences on the mat when I attempted British Amateur Gymnastic Awards as a teenager, I felt somehow proud of Watson for transforming something I had considered a humiliation into such a moving performance. She has the ability to transform the struggle for gymnastic elegance into something that speaks to those who have tried.

Another truly innovative sequence was her progress through the space on the space hopper, usually a fairly ungainly activity but one that Watson turned into a journey which filled her audience with anticipation. She carried us with her as she bounced around the space, turning and turning again each time she reached the perimeter, showing us the strength of persistence and an unexpected poise in the unflattering wobbliness of the activity.

The role of the British Sign Language interpreter was an important part of the overall performance. Rather than standing to the side and providing a 'translation', the interpreter Amy Cheskin formed an integral part of the performance and, as a hearing member of the audience, I found her engagement a hugely enjoyable part of the whole. In particular, her renditions of the music into gesture and rhythm through movement gave everyone in the audience an enhanced sense of belonging in the events that were unfolding. Watson also responded to the accompanying music in a variety of ways and not just through movement in time. She mimed words, breathed feelings, and her facial expressions captured the character of the sounds even in moments of stillness. I was struck by Watson's use of all aspects of the self to express possible meanings in the music.

The reception was very enthusiastic. I saw audience members in tears at the end of the performance. Watson's work speaks to a range of abilities and emotional states in 
a powerful and liberating way. It has a simplicity and a complexity that is hard to describe, but which is rooted in the experiences of those people who are not perfect and who are not always in control, which is most of us, whether we are neurodiverse or neurotypical.

I similarly enjoyed Watson's There's no point crying over spilt milk $(2015)^{2}$, an intriguing performance about childhood and the harsher world we grow up into. -ish is another show which questions deeply, and explores the simple and the complex with power and beauty.

\section{Notes}

1. More information about Watson's research can be found at $<$ https://www.abywatson.co.uk/choreographing-clumsy-dyspraxiaand-choreographic-practice/ $>. . \underline{.1]}$

2. You can still see the trailer for There's no point crying over spilt milk at <https://www.abywatson.co.uk/work\#/theres-no-point-crying-

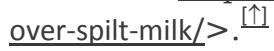

\section{About the review author}

LUCY HOLLINGWORTH is a composer, musicologist and writer currently studying for a PhD at the Royal Conservatoire of Scotland. She has a Master's degree in Composition from Edinburgh University. Her research area is autoethnography and women composers and she is preparing a creative portfolio and a dissertation. Recent performances include, I Lay Down By the Riverside And Dreamed performed by Glasgow New Music Expedition, Out of the Snowstorm, an Owl performed by the Brodick Quartet, What The Living Do performed by Sinae Lee, and a music theatre piece, The Poetess, premiered by students at RCS in 2016. She previously worked as an IT lecturer and web designer and is the Web Editor of the Scottish Journal of Performance. 


\section{Performance review: -ish, by Aby Watson}

TIMOTHY COOPER

DOI: 10.14439/sjop.2019.0601.06

Publication date: 14 July 2019

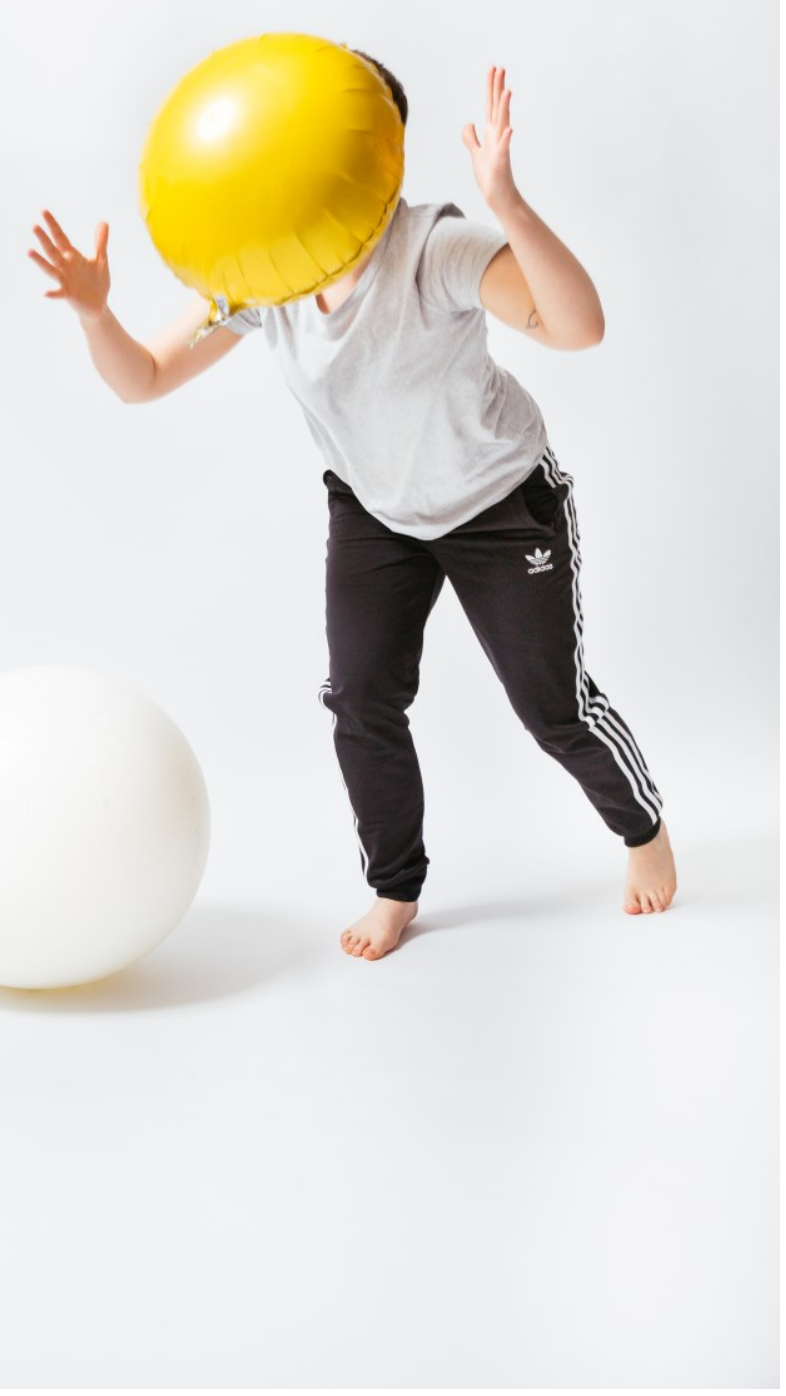

Photo: Jassy Earl Photography 
Scottish Journal of Performance

Volume 6, Issue 1

Saturday 19 October 2018, Tramway, Glasgow

Performers:

Dancer: Aby Watson

BSL interpreter: Amy Cheskin

\section{Introducing -ish}

In October 2018 Aby Watson presented her work -ish at the Tramway in Glasgow. The work explores

... choreography of movement, text and object exploring the murky territory that dyspraxia inhabits between the simple dichotomy of able/disabled. Made and performed by a dyspraxic artist... -ish is a dyspraxic performance of real effort (and momentary chaos) which forms an unapologetic exploration of inbetween-ness that flourishes with and thrives on dys-function (Watson, 2018).

The performance given by Watson and interpreted into BSL by Amy Cheskin was arresting, moving and highly thoughtful. The feeling of the work was characterised by the two performance states Watson creates in -ish. A box was painted on the floor and when Watson entered this space she was 'performing in a formal sense'. Outside of the box she was not performing in the sense of a 'formal' performance: she was performing self, revealing aspects of the creative process through conversational explanations made directly to the audience. Richard Schechner (2013, p.38) argues, '[t]here are limits to what "is" performance. But just about anything can be studied "as" performance". There is not the same manneredness in the out-of-the-box moments as when Watson 'is' performing within the box. This sense of opposition between 'is' and 'as' performance states raises the tension at any point Watson enters the box and allows this to dissipate as soon as she leaves it, and the performance becomes more fragile. 
There were three aspects that I found particularly interesting in this work;

\section{1. -Inherent Choreographies}

Throughout the work Watson performed a series of duets with a variety of objects, notably a space hopper and helium balloons, that explored the inherent motion of these objects. The sight of a helium balloon slowly 'dancing' around the space, occasionally blown by a fan, provided a particularly fascinating play on chance and indeterminacy-every time the balloon seemed to be losing energy it found itself caught in a gust from the fan and gently continued its playful movements around the space. The exploration of the space hopper was more conscious, but no less interesting; Watson used the space hopper to showcase a learnt virtuosity. In her writing she has discussed the problem of virtuosity in her creative work (Watson, 2017). What does it mean for a dyspraxic dancer who identifies as being clumsy and chaotic to master and carefully control movement? Is this contrary to her intent? The answer to this will, I suspect, emerge through future work. But here the mannered and impressive control of the space hopper, as Watson bounced around the box performing perfect 90-degree turns, contrasted beautifully with the chaos of the space hopper thrown against the wall bouncing, sometimes dangerously, back towards Watson.

The movements or 'dances' that the objects undertake become choreography through the framing of the work. It is in the precise parameters, carefully created by Watson, that this occurs. Outside of the world of -ish these movements might be fun, or playful; inside the world of -ish they take on far greater significance. 


\section{Self objectification}

If we are so focussed on the objects in the work, what does that mean for our engagement with Watson as a performer in this space? In the work she seems to use the same choreographic intent to organise her own movements and the objects she works with. Does this make Watson an object within her own work? It certainly means that Watson could be read in an objectified way. Her work focusses on her inherent characteristics and makes the fragilities of her dyspraxia and dyslexia explicit. -ish is not a work where barriers between performer and audience are felt. Watson draws us into the work and presents it in a manner that amplifies and heightens the specific qualities of her movements, celebrating both her clumsiness and her creative exploration of this. All of this adds up to make it impossible to ignore the self in this work.

\section{ExHaustion}

The way the work deals with exhaustion is particularly moving. Watson danced herself to the point of exhaustion in each of the first two sequences; would she sustain this to the end of the work, ending every sequence in exhaustion? As the work progressed it became clear this was not going to be the case and Watson explored a variety of ways of ending sequences. -ish beautifully foregrounds difference, diversity and disability, and as the work ended, I found myself wondering if the moments of exhaustion could be read as a metaphor for the exhaustion expressed by minority groups as they make the case for greater equality in the twenty-first century. A criticism I might make is of the way this exhaustion is paced in the work. Much of the energy is front-loaded and reimagining the sequencing might allow some of the more frenetic energy to be interspersed. This might lead to a more satisfying pacing. However, if -ish is about exhaustion and dissipating energy this might not be in keeping with the content and intent of the work. 


\section{A few words on British Sign Language Interpretation}

In a work centred on diversity, it is important to discuss the BSL interpretation. Amy Cheskin's performance went well beyond translating Watson's speech and the incidental music into BSL language. The interpretation provided a counterpoint to Watson's movement as Cheskin translated the musical and spoken content into a different kind of movement language.

This was made up of Cheskin shadowing Watson around the edges of the space, interpreting her spoken parts and miming a variety of musical instruments that made up the arrangements of the music. Cheskin's body language perfectly matched the understated and conversational tone of the spoken parts, interpreting Watson's manner very effectively. In her interpretation of the music Cheskin's movement perfectly translated its vigorous energy - there was an air of believability in the miming of the different instruments, which was a highlight. If Watson embodied her diversity, then Cheskin embodied the musical personality of the work: the way the two performers interacted was similarly effective with some wonderfully choreographed moments.

\section{References}

Schechner, R., 2013. Performance studies: an introduction. London: Routledge.

Watson, A., 2017. Not [sic]: Choreographing a radically affirmative perspective of dyspraxia. CUK Research Student's Conference. The Royal Conservatoire of Scotland.

Watson, A., 2018. -ish. [online] Available at:

<http://www.abywatson.co.uk/work\#/-ish/> [Accessed 27 Nov. 2018].

\section{About the review author}

TIMOTHY COOPER is a composer and performer of electroacoustic music. In his music he explores new contexts for the sounds he works with. He uses microphones as sonic microscopes and loudspeakers to amplify and heighten the qualities of the sounds he 
Scottish Journal of Performance

Volume 6, Issue 1

records. Recent projects include the site-responsive installation Tide Times made with Laura Bissell and Breathing Space for tuba and electronics composed for Danielle Price.

Tim is a PhD candidate at the Royal Conservatoire of Scotland, supervised by Professor Alistair MacDonald and Dr Diana Salazar. He lectures at the Royal Conservatoire of Scotland and at Edinburgh College. 


\title{
Performance review: Tide Times, by Laura Bissell and Timothy Cooper
}

\author{
GREGOR FORBES
}

DOI: $10.14439 /$ sjop.2019.0601.07

Publication date: 14 July 2019

Between April and August 2018, writer Laura Bissell and electroacoustic composer Timothy Cooper made five visits to Cramond Island as the basis for their multi-disciplinary site-responsive installation Tide Times. Cramond Island is a small tidal island located in the Firth of Forth, just north of Edinburgh on the East Coast of Scotland, accessible by foot across a stone causeway which is left uncovered at low tide and is flanked on one side by an imposing line of concrete anti-boat pylons. The island is less than half a mile long yet packs a rich variety of geographical features: sandy beaches, rocky beaches, hills, cliffs, a wooded area, and a smattering of derelict buildings. Cramond itself is a popular recreational destination and in summer this locale is at its best: a quiet cacophony of bicycle bells, chatting voices, laughing children, seagulls, gusts of wind, the jingle of an icecream van. This is the enticing soundscape that Bissell and Cooper present us with in the ten audio tracks which form the central component of Tide Times.

Tide Times is a multifaceted work. Its resources involve ten audio tracks, which have first to be downloaded onto a phone or mp3 player and listened to whilst walking over the island, and a laminated A4 map which indicates the relevant audio track to listen to at various points on the island. The installation encompasses a remarkably wide framework of artistic and intellectual practices: poetry, epistolary storytelling, field recordings, found objects, treasure-hunting, electroacoustic composition, acoustic ecology, autoethnography and soundwalking. The aim of Tide Times is to invite and encourage the participants to 
explore, create and play in this scenic and intriguing location.

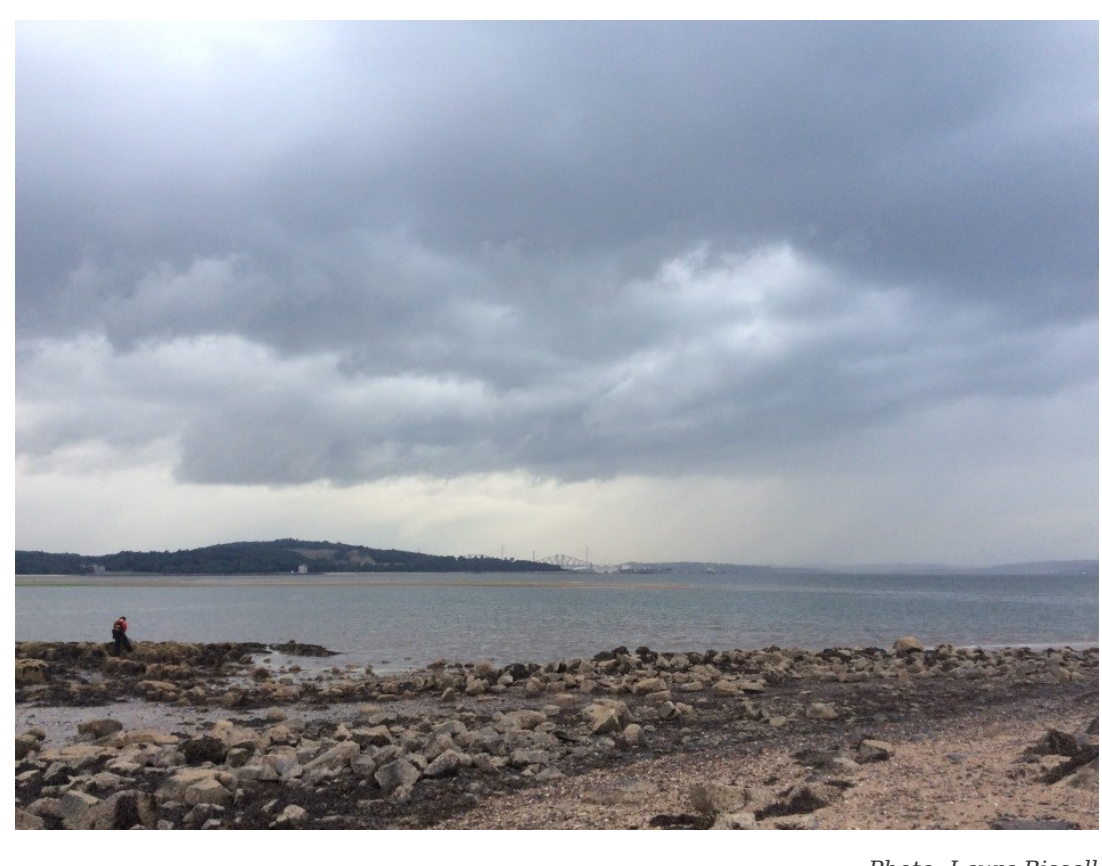

The subjective experience of each individual participant in Tide Times is crucial, but it will always be mediated by the specific experiences of Bissell and Cooper as relayed in the audio tracks-by the way they express and communicate their experiences, and by the way they frame the experience for others. Some of the spoken-word audio tracks involve monologues (mostly by Bissell), some follow a charming 'scripted postcard' conceit between Bissell and Cooper, and some directly address the participants. Altogether, there is rather a lot to listen to42 minutes, to be precise-and possibly too much for those who would rather be instigated by the audio tracks and then left to explore by themselves. Having so much audio may well be an obstacle to having an authentic solitary experience on the island (let alone an interpersonal experience, with each participant isolated by their own headphones). This can make Tide Times feel a little unlived by the end, with the possibility of leaving the island without necessarily having engaged deeply with it on your own terms, although the audio tracks are 
certainly essential as a didactic tool to help guide any hesitant participants.

Some of the most interesting audio tracks are those with Cooper's vivid electroacoustic compositions. They are based on close-microphone field recordings of sounds from Cramond Island and use subtle electronic effects to explore sonic details. Listening to these can help to attune our ears to the ambient sounds of the island and provokes us to make sounds of our own using the natural materials we might find: better than telling us to make music, we are seduced into making music. This is a sophisticated way to help us be like children again: to discover a fresh way of listening to sound, then to try and emulate it. Similarly, there is a childishness to the poetic texts that Bissell uses in her spoken-word tracks but the poems' intentionally naïve onomatopoeic style is likely to appeal to a wide age range. The most effective passages are reflections on the presence of the sea and on what kind of an entity it is.

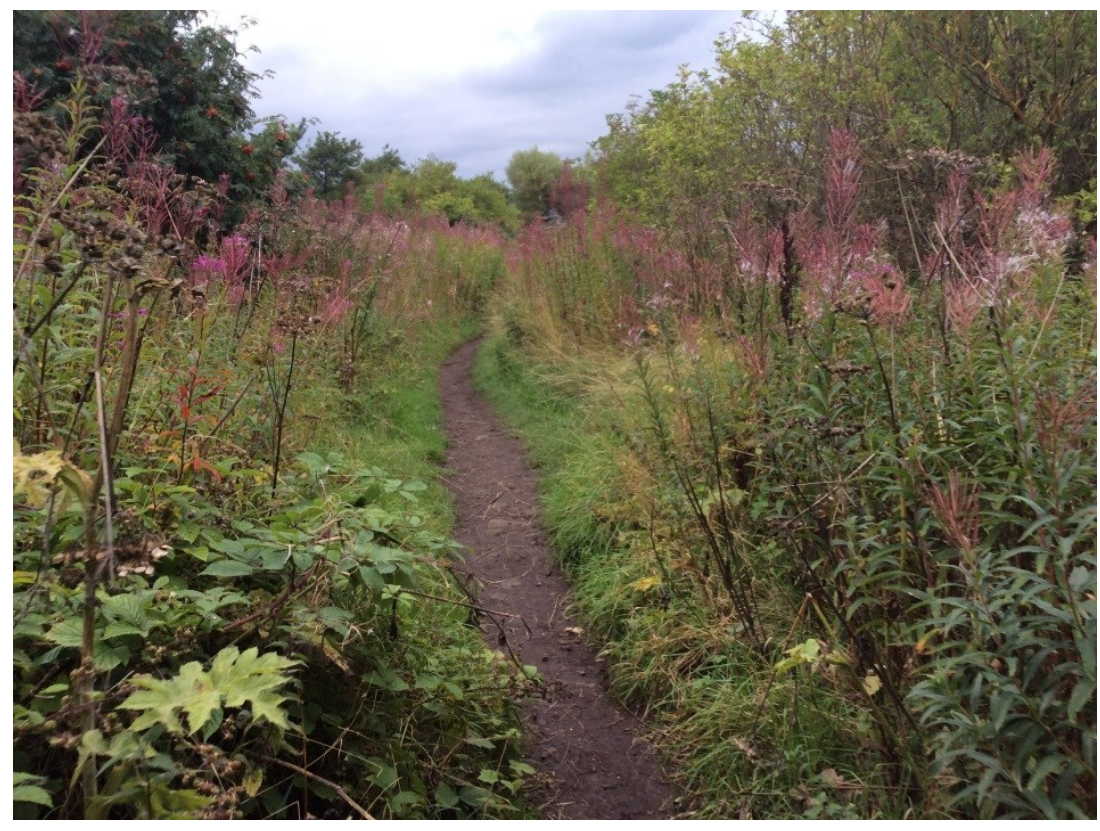

Photo: Laura Bissell

Little is said in Tide Times about the history of Cramond Island, an omission which is well worth considering. In 
brief: there is speculation that a Roman outpost may have settled there but until the early twentieth century the island was used primarily for sheep grazing. Artillery bunkers were built during World War 1 and 2 for protection. Bissell and Cooper seem adamant that Tide Times should remain an experience rooted exclusively in the present moment. Instead of human history, they opt for geological history, referring often to the gradual formation of rocks and mountains, the lifetime of an individual wave, the topography of neighbouring islands, and so on. In any phenomenological experience, a deep and varied sense of temporality is necessary: perhaps an awareness of both human and natural history, would have given the installation a deeper political resonance and made the sense of being there both more transient and more intense.

I visited Cramond Island early in the morning of 28 September 2018. The weather and mood were starkly different from that described in the audio commentary, but having grown up in Edinburgh, I already had good memories of Cramond in its bustling summer peak. This time, the island was windy and cold, overcast with heavy grey-white clouds and melancholy with only a few isolated visitors walking around. The change in atmosphere between the rocky cliffs and the woodland was striking, like a change in pace, or a retreat inwards. The detailed sounds in Cooper's electroacoustic pieces drew me to investigate the materials of the buildings and their acoustical properties. The treasure chests mentioned in the audio tracks, however, were long gone. The experience of Bissell and Cooper worked in counterpoint to my own. While I was there, the site-responsive intentions of Tide Times seemed minimal to my engagement with the island: as a composer, I may have been attentive to the sounds and atmospheres anyway. But, looking back, the intricate, expansive framework created by Bissell and Cooper gave me a unique entrypoint to this island, and the connections they formed between places, sounds and feelings is likely to stay with me for a long time, at least until my next visit. 


\section{About the review author}

GREGOR FORBES is a composer, pianist and conductor based in Scotland. He studied Music at the University of Cambridge and completed a Master's Degree in Composition at the Royal Conservatoire of Scotland in 2016. He has organised and performed in Glasgow Experimental Music Series since 2014, which has now presented fourteen concerts and a workshop in several artistic venues across the city and featured fresh and engaging new music by local and under-represented composers as well as by internationally established figures in experimental music. Gregor is the recipient of the inaugural Hanns Eisler Haus Scholarship and Residency which entails a five-month stay in Eisler's birth apartment in Leipzig to compose music for the Musica Nova Series at the Gewandhaus. Gregor also writes about music for Bachtrack, The Cusp, and his own blog. 
Scottish Journal of Performance

Volume 6, Issue 1 


\title{
Performance review: Creating Intimacy, by Shona Mackay
}

\author{
JAMES SLIMINGS
}

DOI: 10.14439/sjop.2019.0601.08

Publication date: 14 July 2019

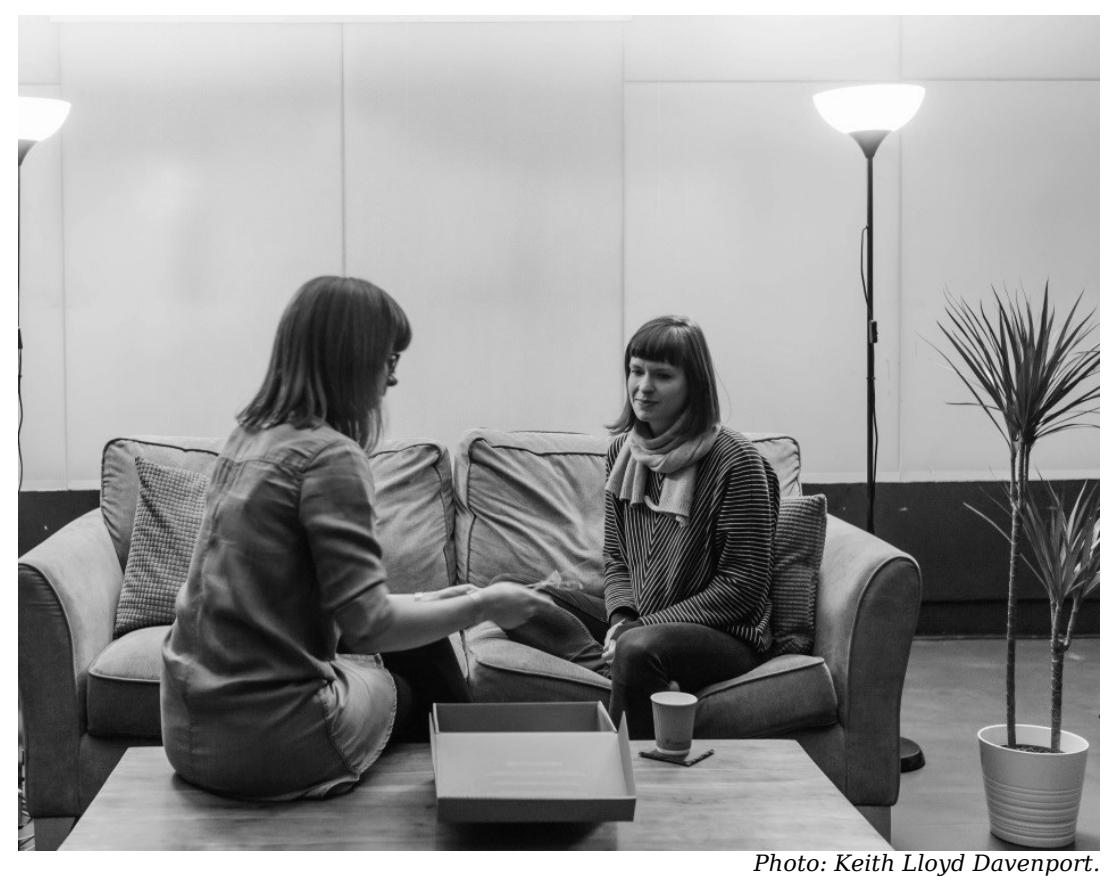

23rd November 2018 CCA, Glasgow

Walking into the familiar surroundings of the foyer of the Centre of Contemporary Arts: Glasgow (CCA) there is a familiar buzz; people sipping lattes and catching up with old friends. The intimacy of these everyday interactions provide the perfect pre-show performance for Shona Mackay's one-to-one experience Creating Intimacy for video, pre-recorded string quartet soundtrack and composer. An usher waiting outside the innocuous sliding door of the cinema took my name and proceeded to sit me down just outside the door with an audio introduction to the work. The headphones cut out the various conversations happening around me that had begun to seem like a performative ritual of its own, and the voice 
of the composer, an integral part of this whole performance, welcomes me to the piece. All this provides a layer of expectation that makes it very clear that this is not a string quartet in the traditional sense. I am invited to take my shoes off and proceed into the cinema.

The vestibule smells reassuringly of incense-I remove my shoes and politely knock on the door to the cinemacome-performance space. The familiarities of this between space, not quite part of the performance, but not far from it, reminded me very much of waiting in the wings before going on stage. I felt as much performer as I did audience, I just didn't have my shoes.

I am greeted by the composer and walk into a space that seems at once familiar and homely, as well as carefully curated and formalized as now being in the performance. The 'set' includes a sofa, rug, and coffee table. In a corner sits a piano and music stand, with a score resting on it. The atmosphere is one of welcome and comfort. I am offered a cup of herbal tea, cinnamon to match the incense, which I accept and I luxuriate in rubbing my toes in the soft pile of the rug.

Mackay is an integral part of this performance. She acts as host to the guest she has brought into a space that exists as her living room in the performance, and which contains furniture from her living room in real life. The introduction and conversation is followed by some joint breathing exercises and Mackay introduces a box of personal trinkets, each with an associated memory, that are provocatively placed on the table in front of us. The conversation is drawn to any similar box that I own and I spend too long talking about brown archive boxes, and table tennis games.

Headphones are placed over my ears and the prerecorded music of the string quartet begins to play. I close my eyes and fully immerse myself in the music. A further stimulation dawns with the opening of my eyes; 
the piece is accompanied by film and now the atmosphere shifts from the delicately composed quartet. In a piece describing intimacy, touch between two humans is one of the more obvious places to start. The film shows the composer herself, and her partner in various embraces, with tender and loving caresses of various parts of their naked forms. While it would have been easy for this to have become sexualized, the film is much gentler and more loving than that, much more akin to Adrien Howells The Pleasure of Being: Washing/Feeding/Holding.

The cinematography perfectly matches the unpretentious score; everything has its place, and I am guided through the narrative of the work. Nothing about the experience is difficult, and the gentle polyphony of the strings mirrors the soft-focus intimacy between the composer and her partner.

The précis to the third and final movement of this three movement string quartet was an exploration of the silent box of memory laden trinkets that had kept vigil throughout the performance. Mackay invited me to share a gesture of intimacy with her during the final movement of the work, the decision regarding this gesture was given to me and I was free to choose a gesture that resonated personally. From the box in front of me, I was drawn to the green, cloth bound book that reminded me of an edition of The Wind in the Willows I own. I did not realize this was a personal diary of the composer and as our gesture we negotiated turning pages, with Mackay occasionally drawing my attention to a piece of text. The music of this movement somewhat underscored what became a conversation of sharing of stories, such as where my father taught me to skim stones, and a trip around Europe by Mackay. This choice to speak during the performance of the music was not something conscious, used to subvert the music, but seemed like the next logical part of our joint experience. Given the impetuous on the participant to guide this moment, it would be possible to miss the third movement altogether. 
As the music drew to a close, I finished my tea, collected an origami memory that Mackay had been making as I listened to her music and left, feeling a great connection to the piece as a whole, and with a desire to hear the score again.

This was an accessible, personal, and extremely well curated work of performance art. It was immersive in every sense (and with every sense) and guided by the presence of the composer. I found the music to be wellcrafted and clear, with punchy counterpoint reminiscent of Tippett's Concerto for Double String Orchestra, but the gentle lyricism of Delius. Undoubtedly this was a piece of film music scored for string quartet, the music syncing to the cinematography deftly, but it was not necessarily the notated score that was the stand out for me.

The 5th instrument in this piece, the composer herself, is the finest part of this immersive performance, and the most memorable part of the experience for me. While it would be easy to dismiss this as a gimmick, the way that each interaction and experience for the audience had been thought through and curated gave the whole score (in its widest possible meaning) a legitimacy as a piece of work that coalesces as a cohesive whole.

Leaving the temporal shelter of the performance space, I could hardly believe that my 30 minute slot was over. Breaking that narrative tension and walking back out in to the real world of Glasgow, I felt that I had not merely listened to, or observed a piece of work, but experienced something else. My origami swan in hand, the intimacy that was created in that performance space was not only an intimacy between composer and work, but also an reconnection with my own self, the memories it evoked were strong, visceral, and sometimes forgotten. Looking at my memento now evokes a different memory, a different feeling, but each of them intimate. 


\section{About the review author}

JAMES SLIMINGS is a final year $\mathrm{PhD}$ student at the Royal Conservatoire of Scotland researching Choral Blend. He has delivered papers at the Conservatoires UK Research Student Conference (Glasgow); Music, Education and Technology Symposium (London); International Symposium on the Histories and Practices of Choral Singing (Lund); and the Scottish Graduate School of Arts and Humanities Doctoral Showcase (Glasgow). This summer he will present at the Oxford University International Conducting Studies Conference in Sydney. He is also a quality assurance reviewer for MUSIQUE and QAA Scotland, and has given talks on Post-Graduate Research studies for the Scottish Funding Council and the Association of European Conservatoires. 
Scottish Journal of Performance

Volume 6, Issue 1 


\title{
Book review: Twenty theatres to see before you die: a love letter to Britain's theatres, by Amber Massie- Blomfield
}

\author{
BEN FLETCHER-WATSON
}

DOI: $10.14439 /$ sjop.2019.0601.09

Publication date: 14 July 2019

Twenty theatres to see before you die: a love letter to Britain's theatres, by Amber Massie-Blomfield. London: Penned in the Margins, 2018; ISBN: 9781908058454 (f14.99)

Ask anyone who loves theatre to list their favourite venues, and you'll undoubtedly receive a unique selection, whether large or small, extant or demolished, real or imaginary. People might choose the first auditorium they ever visited; rhapsodise over the stage on which they performed in youth theatre; celebrate the building where they got their first job; talk about that wild show on a clifftop, or in a field, or under a railway arch, or winding through a town centre. Amber MassieBlomfield's lyrical paean to Britain's theatrical estate ticks off all these and more, from the Minack to Mull, noting that when she explained her project to the people she met on her travels, this routinely resulted in 'everyone jostling to explain why their proposed theatre is more deserving of being on this list than any other. They're all right, of course' (p.294).

Her survey takes in the Roman auditorium of Verulamium in St Albans, Belfast's Grand Opera House, designed by Frank Matcham in the gloriously garish Oriental style, Battersea Arts Centre just before it reopens, and that other 'national theatre without walls' in Wales. Theatres 
the size of countries, theatres 10-metres-square; all are included in this capacious and inclusive text.

At its heart, the book is about theatre as space. MassieBlomfield returns again and again to the concept that spaces can be-must be-shared: 'being with other people is better than being alone... Sharing space is the beginning of kindness' (p.339). An auditorium without an audience can still be a place where work happens, but only by inhabiting it for the purpose of watching a story unfold do we create the theatron, or seeing-place. Our communal act of seeing (before we die, as the seemingly clickbait title jokes) becomes an act of place-making.

Her chapter on Edinburgh's Summerhall epitomises this concept. Massie-Blomfield quotes Chris Goode: 'At its best, you can live inside theatre... theatre's what I think with' (p.115). Later she builds on this with the statement, 'Edinburgh. If you can live inside theatre, this is where the idea becomes manifest... the city is a stage' (p.171). She talks about muscle memory as she traverses the centre of Edinburgh, feeling the physical impact of its cobbles and wynds. Space explodes as the city transforms each August, performance bleeding from one venue into the next like traffic noise. Memories of Action Hero's Watch Me Fall five years earlier blur with her experience of an unnamed show in Summerhall's Anatomy Lecture Theatre; in the same way, we find ourselves casting our minds back to previous shows as we take our seat in a venue, memories populating the space alongside actual companions. Here, Summerhall is a synecdoche for Massie-Blomfield's deliberately quote-marked 'Edinburgh'-by which she means the festivals, not so much the city-where bars are piled on top of theatres and ringed with exhausted flyerers. She astutely notes that 'this building is still becoming itself, stranded between its identities as a scientific institute and an arts venue' (p.179), very much in keeping with the long tradition of Edinburgh's most famous dualisms, from Wringhim / Gil-Martin to Jekyll / Hyde and even fur coat / nae knickers. The rich blend of architectural critique, historical context, knowledge of contemporary theatre 
and sheer love for the art-form in this chapter brings the building to life, whether you know it intimately or have never crossed the Tweed.

This is an accessible text that wears its scholarship lightly; Massie-Blomfield avoids theory-heavy discussions of the public sphere, preferring instead to push into the intimate histories of the people behind the theatres. This approach highlights both the malarial grip of theatremania on individuals (with which many readers may have sympathy) and the quixotic, generous, maddening, stubborn, open-minded, practical personalities needed to juggle the often overwhelming demands of venue management. Rowena Cade, who built the Minack Theatre by hand on a Cornish cliff-top over many years, stands as a ghostly reminder of this tendency: 'how she realised her remarkable vision through decades of arduous labour and sheer bloodymindedness is, for me, one of the most inspiring stories of holding faith in theatre' (p.33). I have visited the Minack a number of times, as spectator, actor, technician and car-park attendant, and its wild mythology never fails to capture the imagination. The scrappy Portakabins that serve as dressing-rooms, teetering above the sea, speak just as eloquently of Cade's can-do attitude as the serried ranks of hand-carved concrete seats where punters unpack their sandwiches as the show begins. I once watched a basking shark swim lazily round the rocks from stage-left to stage-right during a weekend matinée, and wondered whether Cade had dreamed of these impossible encounters at the same time that she designed the stage.

From the start, Massie-Blomfield acknowledges the deeply personal choices she has made without defensiveness. My list would be different (although there would definitely be overlap), as would yours. I can only join with the author in saying: 'Start your own list. Have your own adventure' (p.25). This book would make a fine road-map, but there's even more fun to be had in creating your own. 


\section{About the review author}

DR BEN FLETCHER-WATSON manages the Institute for Advanced Studies in the Humanities at the University of Edinburgh. His research explores performance for non-traditional audiences, including babies, people with dementia and spectators on the autism spectrum. He was a founding editor of the Scottish Journal of Performance. 